Research Article

\title{
Green Product Design and Pricing Decisions in a Risk-Averse Supply Chain under Alternative Power Structures
}

\author{
Tiantian Xu $(\mathbb{D}$ and Jizhou Zhan \\ School of Business, Nanjing Audit University, Nanjing 211815, China \\ Correspondence should be addressed to Jizhou Zhan; jzzhan@aliyun.com
}

Received 8 June 2020; Revised 26 February 2021; Accepted 8 March 2021; Published 24 March 2021

Academic Editor: Viacheslav Kalashnikov

Copyright (C) 2021 Tiantian Xu and Jizhou Zhan. This is an open access article distributed under the Creative Commons Attribution License, which permits unrestricted use, distribution, and reproduction in any medium, provided the original work is properly cited.

\begin{abstract}
Motivated by the prevailing green product design and the different supply chain power structures, this paper aims to analyse the role of power relationship and risk-aversion in economic and environmental performance of sustainable supply chain. Three game theory models, including the manufacturer Stackelberg (MS) model, retailer Stackelberg (RS) model, and vertical Nash (VN) model, are developed to study the pricing and greenness level decisions in a two-echelon sustainable supply chain, where one riskaverse manufacturer sells green products through one risk-averse retailer. This paper shows that when selling through a more riskaverse retailer, the risk-averse manufacturer prefers to provide a product with a higher level of greenness and achieve a greater utility regardless of the power structure. A manufacturer as a follower may have stronger motivation to increase the product's level of greenness than one in a more balanced supply chain when the green technology investment coefficient is sufficiently low. With regard to the power structure, the channel leadership is not necessary to for the manufacturer to achieve higher utility, which depends on the green technology investment coefficient, greenness level sensitivity, and players' risk aversion.
\end{abstract}

\section{Introduction}

In today's marketplace, progressive enterprises recognize that sustainable operations are crucial for long-term development [1]. Firms in different industries have begun to use various methods to improve the sustainability of their operations and the greenness level of their product, such as using recycled or green materials, integrating pollutionabatement facilities, and reducing the volume of package materials $[2,3]$. For instance, to increase the greenness level of products, Gree, a Chinese electric appliances' manufacturer, insists on sustainable investment by integrating environmental considerations into the design of their products to diminish the energy use and carbon emission. In the food industry, Starbucks takes environmental protection and sustainability as part of its core business model. To reduce the amount of plastic used in their product packaging, they have started to use direct drinking lids instead of plastic straws based on their continuous research and development. Meanwhile, straws made from paper or other biodegradable materials are offered to consumers who buy items containing cream. Even though the adoption of sustainable practices can increase the greenness level of a product and thus boost demand, it often requires substantial investment $[3,4]$. Within a supply chain, manufacturers generally shoulder the responsibility for designing and producing green products while the investments in sustainable development may benefit other participants [5]. For example, the retailer can satisfy environmentally conscious consumers by selling green products without incurring any direct green investment costs. Hence, when designing green products, manufacturers should not only pay attention to the trade-off between costs and benefits but also consider the decisions of other players in the supply chain. Consequently, it is imperative for the manufacturer to make a thoughtful trade-off to make green product design decisions in the supply chain.

There is always a power differential between supply chain participants, and the specific sequences of decision making by participants is different in different power structures $[6,7]$. Larger firms tend to have stronger bargaining power, 
which enables them to make decisions first as leaders, thus influencing the economic and environmental decisions of comparatively weaker players. In this way, powerful retailers can encourage suppliers to produce more energy-efficient products to reduce their negative impact on the environment. Walmart, for example, had once announced that its stores in U.S. and Canada would only sell the compacted versions instead of big bottles of detergent [2]. However, there are also some big manufacturers, such as Procter \&Gamble and Unilever, who can design their products in their own way when selling them through small corner stores. Moreover, in a more balanced supply chain, two players often take decisions simultaneously. As power shift can influence the decisions and profits of supply chain participants [7], theoretical game models are developed in this study by considering three power structure scenarios. These models included the manufacturer Stackelberg (MS) model (where the manufacturer is comparatively more powerful than the retailer and takes decisions first), the retailer Stackelberg (RS) model (where the retailer as a leader makes decisions first), and the vertical Nash (VN) model (where the manufacturer and the retailer make decisions at the same time). Accordingly, another aim of this paper is to evaluate how economic and environmental performance of risk-averse players depends on the supply chain power structures.

In practice, firms often operate in an uncertain environment due to a number of random factors. Offering new green products can be more risky. For instance, Honda developed electric-powered technology and entered the new energy market with its electric car, the Fit EV, in 2012. However, the sales for this model were not very good [8]. It is not always easy to anticipate consumer purchasing behavior owing to the new environmental attributes of the product even though eco-labels are given out. Consumers can then return the overestimated product to the retailer with money back guarantee policy. Fashion retailers, such as Gap and ASOS, always shoulder the costs that are associated with the return [9]. As both the manufacturer and retailer may bear risk costs, effective risk management is crucial to achieving both economic and environmental performance in sustainable supply chains. We consider a supply chain with riskaverse players who are comparatively conservative and dislike the volatility in investment. So, when making decisions, they consider not only the benefits but also the potential risk [10]. Accordingly, one of primary aims of this study is to explore the dependence of sustainable supply chain performance on the degree of risk aversion for the participants.

In existing literature regarding sustainable supply chains, the impact of power structures on risk-averse participants has been largely ignored. In this study, the joint impacts of power structures and players' degree of risk aversion on equilibrium results and sustainable supply chain performance are considered. Hence, a supply chain with one riskaverse retailer and one risk-averse manufacturer who is capable of investing in sustainable development is studied to identify the design of the green product. Consumers in the marketplace are sensitive to the level of product greenness and retail price. The optimal decisions and utilities of players are given out, respectively, in three different power structures, i.e., the manufacturer Stackelberg (MS), the retailer Stackelberg (RS), and the vertical Nash (VN). Moreover, comparative analysis is employed to investigate how the equilibrium results depend on the power structure when supply chain participants are risk-averse. Finally, new managerial insights are also presented based on numerical analytical results. The remainder of this paper is organized in the following manner. Section 2 provides a review of existing research. Section 3 presents the main model, and Section 4 describes the players' equilibrium decisions in the three different power structures. In Section 5, the effect of the power relationship on the sustainability performance of the supply chain is examined together with numerical analytical results. In Section 6, the managerial implications of this study and possible future work are discussed.

\section{Literature Review}

Three streams of research in operations management (OM) are closely related to this work, including (i) green product design issues in supply chains, (ii) supply chain power structure, and (iii) risk management. Studies contributing to these three fields are reviewed here, respectively.

2.1. Green Product Design Issues in Supply Chains. There are increasing concerns about sustainability, which contain various aspects, such as carbon emission control [11, 12], corporate social responsibility [13], eco-efficient innovation [14-18], and product line design decisions regarding green and nongreen products $[19,20]$. Many researchers incorporate sustainability issues into traditional operational problems, such as [14], which analyze the development trends and opportunities in social and environmental objectives within OM research. Sustainable investment can be adopted by either manufacturers or retailers $[4,15,16]$, and governments are important participants as environmental policies can be an effective tool to encourage investment in sustainable efforts $[11,17]$. When considering sustainable investment, there is a fundamental trade-off between the environmental impact and economic cost [3]. In the supply chain, the sustainable investment levels can be affected by the behaviors of other participants [18, 21, 22]. Kartick et al. [23] investigate the green product design problem in a twophase setting with different power structures and retailer's procurement strategies. Yang et al. [24] study the influence of channel structure choice on green decisions and find that the dual-channel approach is an effective method to improve sustainable investment. Guo et al. [25] find that both the competition and the increase of the consumer return rate will decrease the retailers' investment in green technology in a supply chain with one manufacturer and two retailers. To improve supply chain sustainability, some coordination mechanisms and contracts are also studied [13, 15, 26, 27]. Jaber et al. [27] examine the coordination problems in the context of emissions limits. Ma et al. [13] analyze contract design in asymmetry supply chain, in which supply chain 
participants both invest in corporate social responsibility and invest in service. Allah et al. [28] compare three different supply chain contracts in Nash and Stackelberg games and demonstrate that a wholesale price contract can coordinate the sustainable supply chain. In contrast to the existing literature, this study examines the impact of the players' risk aversions on the green product design in a two-stage supply chain with uncertain demand.

2.2. Supply Chain Power Structure. The influences of power structure on the performance of the traditional supply chain have been well studied under various conditions, such as demand types [29, 30], competition structures [31, 32], and coordination contracts [33]. Li et al. [34] show that supply chain leaders can always obtain higher profits in competing supply chains with substitute products. Shi et al. [29] consider a game theoretic model in a supply chain with random and price-dependent demand, which reveal that whether firms with more channel power can obtain more profit rely on the expected demand. Luo et al. [35] explore the impact of the power structure on the retailer's product choice and price decisions, and they find that product choice is independent of the power structure, while price decisions and supply chain performance can be affected by different power structures. Yu and Xiao [36] show that more channel power for suppliers does not mean higher profit in a supply chain with one supplier, one retailer, and one third-party logistics provider. In a sustainable supply chain, Touboulic et al. [37] find that the power structure can prominently influence the sharing of sustainability cost and value between players through qualitative analysis. Chen et al. [38] examine the effect of the power structure on sustainability and the coordination of the supply chain with two-part tariff contract. They find that a more balanced power structure is good for the entire supply chain and the consumers. Shen et al. [39] show that when considering the advertisement, the pricing leadership is not necessary for the green supply chain to gain the largest profit. Also, they indicate the higher substitutability between green and nongreen products is harmful to the environment. Different from the existing literature, we consider the green product design decisions in a supply chain with risk-averse participants. We focus on the impacts of power structure together with risk behaviors of players on the greenness level and pricing decisions in this study.

2.3. Risk Management. Supply chain operations can be disrupted by various factors in practice, so supply chain risk management is an important topic to consider [40]. A detailed review on this topic is presented by Tang [41]. Mean-variance method is a commonly used method to explore the impact of risk on operational decisions, such as order quantity [42, 43], price [44-46], service levels [45], and supply chain contracts design $[6,47]$. Xiao and Yang [45] analyze the impact of competition and the retailer's risk aversion on the equilibrium results in two supply chains with one risk-neutral supplier and one risk-averse, respectively. The main findings indicate that the optimal retail price and level of service decrease as the risk sensitivity of the retailer increases and the impact of risk sensitivity on the wholesale price depends on the substitutability of the two products. Choi et al. [48] consider a supply chain with not just riskaverse retailers but risk-averse manufacturer. They find that the profit of the supply chain will be lower under the competition environment when the players have higher degree of risk aversion. Players' risk behaviors are also considered in sustainable supply chains [6,9]. Chan et al. [9] explore the coordination mechanism in a supply chain with one risk-averse retailer, where the environmental cost is closely related with the environmental taxes. Niu et al. [6] consider the performance of the sustainable supply chain with buy-back contract. They find that the sustainability of the supply chain increases when the manufacturer's lossattitude increases. However, in their study, the sustainability is measured by the equilibrium quantity and the retailer is risk-neutral. This work is close to Xie et al. [49], who investigate the impact of the manufacturer's degree of the riskaverse on quality and price decisions. However, the wholesale price is an exogenous variable in their paper. In this paper, the mean-variance method is used to investigate the impact of risk-averse behaviors of both the manufacturer and retailer on the green product design decisions with endogenous wholesale price.

2.4. Research Gap and Contributions. In summary, we contribute to the literature in the following ways. Firstly, most studies related to sustainable issues focus on the coordination contract design and cooperative green investment decisions in the supply chain to improve supply chain economic and environmental performance. This paper considers the influence of uncertain demand on the manufacturer's green technology investment and retailer's pricing decisions. Moreover, the majority works on supply chain risk management ignore the specific green product development. We investigate how supply chain participants' risk-averse towards uncertainty affect green product design and pricing decisions. Furthermore, we analyze how product greenness and pricing are affected by participants' risk aversion, green technology investment coefficient of the manufacturer, demand volatility, and greenness level sensitivity. In addition, comparative analysis is presented to show how the optimal decision variables and utilities depend on the channel power structure under uncertainty.

\section{The Basic Model}

A supply chain with one risk-averse retailer and one riskaverse manufacturer is considered, where the manufacturer is engaged in selling the product to the retailer at a wholesale price, and the retailer further sells the product to the environmentally conscious customers. The manufacturer invests to developing green technology to enhance the product's level of greenness, which has positive effects on demand. And, the green investment benefits both the manufacturer and the retailer as demand expands. In this paper, the "greenness level" of the product is assumed to 
mean its environmental performance, which can be improved by using recycled or green materials, reducing greenhouse gas emission during operational process or cutting down energy consumption in the use stage [2, 3]. For instance, in the fashion industry, H\&M improves the greenness level by using organic or recycled cotton in the product development process [23]. In the food industry, Coco-Cola Company uses renewable resources as much as possible in packaging [16]. Similar to previous studies $[15,36,50,51]$, it is assumed that the cost function of investment is $h e^{2}$ for the greenness level $e$.

Market demand can be influenced by the retail price and product's level of greenness, and thus, a random linear demand function is assumed for the retailer, $\widetilde{D}(p, e)=$ $\tilde{a}-b p+\beta e$. As changes in business, economic, and other conditions may occur, the market demand can be uncertain, so we assume $\tilde{a}$ is a random variable with mean $\bar{a}$ and variance $\sigma^{2}$. The level of product greenness is determined by the manufacturer's investment in green technology. In the basic model, the prices and the product's greenness level are investigated under different supply chain power structures, i.e., the manufacturer Stackelberg (MS), the retailer Stackelberg (RS), and the vertical Nash (VN).

The notations are summarized as follows:

$\tilde{a}$ is the stochastic market base with mean $\bar{a}>0$ and variance $\sigma^{2}$

$c$ is the unit production cost of manufacturer, $c>0$

$b$ is the sensitivity of market demand to the retail price, also referred to as price sensitivity

$e$ is the greenness level of the product, $0<e<1$

$\beta$ is the sensitivity of market demand to the product greenness level, referred to as the greenness level sensitivity

$w$ is the unit wholesale price of the manufacturer, $w>c$ $p$ is the retail price of the retailer, $p=m+w$, where $m$ is the retailer's unit marginal profit

$\lambda_{j}$ represents the constant degree of risk aversion for the players towards uncertainty, $j=r, m$

$h$ is the green technology investment coefficient of the manufacturer, $h>0$, with a larger coefficient $h$ resulting in a lower technology investment efficiency $(1 / h)$

$\tilde{\pi}_{r}^{i}\left(\tilde{\pi}_{m}^{i}\right)$ is retailer's (manufacturer's) random profit in $i$ supply chain power structure, where $i=m, r, v$ denote the MS, RS, and VN power structures, respectively

Based on the above settings, the random profit of the retailer can be expressed as $\tilde{\pi}_{r}^{i}=(p-w)(\widetilde{a}-b p+\beta e)$, while the random profit of the manufacturer is $\tilde{\pi}_{m}^{i}=(w-$ c) $(\tilde{a}-b p+\beta e)-h e^{2}$.

In the random demand circumstance, vendor managed inventory and quick respond are commonly used methods in the supply chain [52-54]. Under these supply chain modes, the retailer does not need to bear inventory cost as the supplier can satisfy the demand quickly. As Xiao and Yang [45], we assume the supplier can flexibly fulfill the orders from the retailer to focus on the impact of demand uncertainty on the green product design strategy. Hence, both the manufacturer and the retailer should bear operational risk when facing random demand, so it is inevitable to investigate the behavior of the participants. Similar to Tsay [46] and Agrawal and Seshadri [55], this study investigates the case where the players measure the random profits based on the meanvariance method. The risk of the player is evaluated by the variance of the profit.

Thus, retailer's utility can be expressed as

$$
\begin{aligned}
u_{r}^{i}(p, w, e) & =E\left(\tilde{\pi}_{r}^{i}\right)-\frac{\lambda_{r}}{2} \operatorname{Var}\left(\tilde{\pi}_{r}^{i}\right) \\
& =(p-w)(\bar{a}-b p+\beta e)-\frac{\lambda_{r}}{2}(p-w)^{2} \sigma^{2},
\end{aligned}
$$

where $\lambda_{r}(\geq 0)$ is the retailer's degree of risk aversion. $\lambda_{r}=0$ means the retailer is risk-neutral. The first term of equation (1) represents the expected profit, while the second term is the retailer's risk-related cost generated by the random profit. Similarly, the manufacturer's utility can be expressed as

$$
\begin{aligned}
u_{m}^{i}(p, w, e) & =E\left(\tilde{\pi}_{m}^{i}\right)-\frac{\lambda_{m}}{2} \operatorname{Var}\left(\tilde{\pi}_{m}^{i}\right) \\
& =(w-c)(\bar{a}-b p+\beta e)-h e^{2}-\frac{\lambda_{m}}{2}(w-c)^{2} \sigma^{2}
\end{aligned}
$$

where the first term is the expected profit, the second term is the green technology investment cost, and the last term is the risk-related cost. To guarantee the concavity of the utilities of the participators, we assume $h>\left(\beta^{2} / 2\left(2 b+\lambda_{m} \sigma^{2}\right)\right)$, which is consistent with the assumptions in previous studies $[5,56]$. Also, in practice, the technology investment is always not cheap.

This paper first develops the models under MS, RS, and VN supply chains. The equilibrium level of greenness and prices under different power structures are compared. Both participants quit the game once negative utilities are reached. The specific sequences of the games are as follows.

In the MS setting, the manufacturer acts as the leader while the retailer is the follower, so (1) the manufacturer simultaneously determines the product's level of greenness $e$ and the wholesale price $w$ and (2) the retailer sets the retail price $p$.

In the RS setting, the manufacturer is the follower, while the retailer is the first to act, so (1) the retailer decides the marginal profit $m$, where $m=p-w$, and (2) based on the marginal profit of the retailer, the manufacturer establishes the wholesale price $w$ and the product's level of greenness $e$.

In the $\mathrm{VN}$ setting, the manufacturer and the retailer take their decisions simultaneously. More specifically, the manufacturer decides the product's level of greenness and the wholesale price to optimize utility, anticipating the retailer's marginal profit, while the retailer decides its marginal profit. 


\section{Equilibrium Strategies under Different Power Supply Chains}

The equilibrium results under the manufacturer Stackelberg (MS), the retailer Stackelberg (RS), and the vertical Nash $(\mathrm{VN})$ settings are presented, respectively.

4.1. Manufacturer Stackelberg (MS) Setting. By using the backward induction technique, the subgame perfect Nash equilibrium can be solved, which is summarized in Proposition 1. All proofs are presented in the Appendix.

Proposition 1. The optimal greenness level and the wholesale price are $e^{m *}=\left(A^{2}(\bar{a}-b c) \beta / 4 A b h\left(b+\lambda_{m} \sigma^{2}\right)+2 h \lambda_{m} b^{2} \sigma^{2}+\right.$ $\left.A^{2}\left(4 b h-\beta^{2}+2 h \lambda_{m} \sigma^{2}\right)\right)$ and $w^{m *}=(2(\bar{a}-b c) h A(A+b) /$ $\left.4 A b h\left(b+\lambda_{m} \sigma^{2}\right)+2 h \lambda_{m} b^{2} \sigma^{2}+A^{2}\left(4 b h-\beta^{2}+2 h \lambda_{m} \sigma^{2}\right)\right)+c$ and the optimal retail price is $p^{m *}=\left(2(\bar{a}-b c) h\left(A^{2}+2 A b+\right.\right.$ $\left.A \lambda_{m} \sigma^{2}+b \lambda_{m} \sigma^{2}\right) / 4 A b h\left(b+\lambda_{m} \sigma^{2}\right)+2 h \lambda_{m} b^{2} \sigma^{2}+A^{2}(4 b h-$ $\left.\left.\beta^{2}+2 h \lambda_{m} \sigma^{2}\right)\right)+c$, where $A=b+\lambda_{r} \sigma^{2}$.

Inserting the optimal decisions, $e^{m *}, w^{m *}$, and $p^{m *}$, into equations (1) and (2), the equilibrium utilities for the manufacturer and the retailer can be expressed as equations (3) and (4):

$u_{r}^{m *}=\frac{2(\bar{a}-b c)^{2} h^{2}\left(2 A-\lambda_{r} \sigma^{2}\right)\left[b \lambda_{m} \sigma^{2}+A\left(b+\lambda_{m} \sigma^{2}\right)\right]^{2}}{\left[4 A b h\left(b+\lambda_{m} \sigma^{2}\right)+2 b^{2} h \lambda_{m} \sigma^{2}+A^{2}\left(4 b h-\beta^{2}+2 h \lambda_{m} \sigma^{2}\right)\right]^{2}}$,

$u_{m}^{m *}=\frac{A^{2}(\bar{a}-b c)^{2} h}{4 A b h\left(b+\lambda_{m} \sigma^{2}\right)+2 b^{2} h \lambda_{m} \sigma^{2}+A^{2}\left(4 b h-\beta^{2}+2 h \lambda_{m} \sigma^{2}\right)}$.

The results of Proposition 1 indicate that when the mean market base $(\bar{a})$ increases, both the retailer and the manufacturer increase prices to obtain a higher marginal cost. Meanwhile, the manufacturer increases the product's level of greenness to further boost the expected demand. In addition, when the green technology investment efficiency $(1 / h)$ and the greenness level sensitivity $(\beta)$ increase, the manufacturer increases the greenness level to obtain a higher expected demand. Furthermore, the retail price and wholesale price are increased to obtain higher marginal profits.

To further explain the effect of the volatility of demand and the price sensitivity on the greenness level and prices of the product, Figures 1 and 2 are depicted, where the values of the parameters used are $\bar{a}=10, \lambda_{m}=1, \lambda_{r}=1.5, \beta=1.5$, $b=2, c=1$, and $h=1$.

Figures 1 and 2 show that, as the volatility of demand increases, the manufacturer prefers to provide a product with a lower level of greenness and wholesale price to the retailer. Thus, the retail price also decreases. Intuitively, the risk-related costs of the manufacturer and the retailer are comparatively larger due to the higher degree of uncertainty. Therefore, they set lower prices to reduce their risk-related costs. Furthermore, Figure 2 indicates that the greenness level decreases as the price sensitivity decreases whenever the price sensitivity is larger or smaller than the

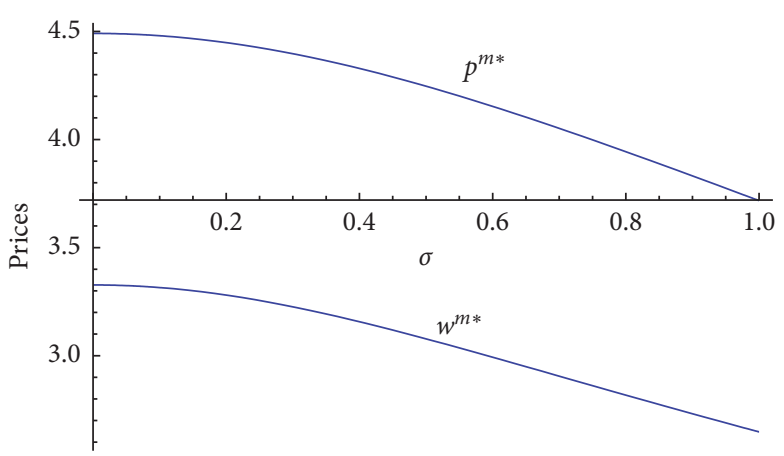

FIgure 1: Prices versus the demand volatility.

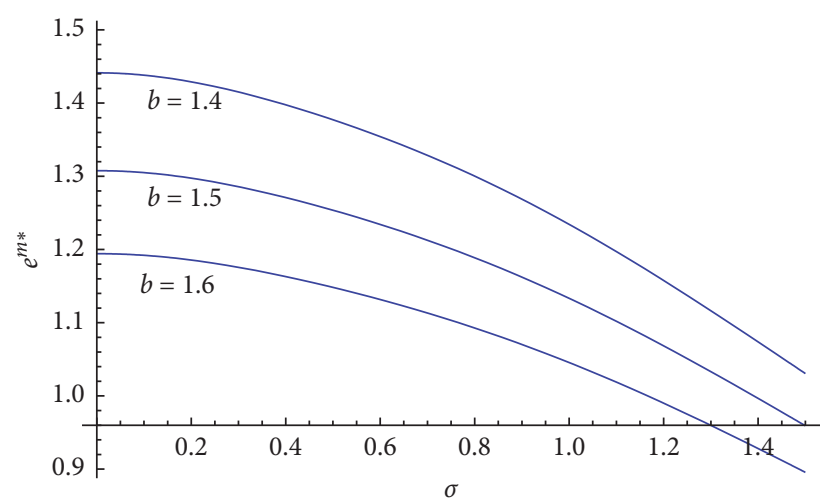

Figure 2: Greenness level versus demand volatility and price sensitivity.

greenness level sensitivity. That is, as the price sensitivity increases, the manufacturer tends to decrease the wholesale price to attract more consumers. As a higher greenness level means a higher investment cost, the manufacturer also decreases the level of greenness. Finally, Figure 2 shows that the differences between different price sensitivities become smaller when the volatility of demand increases, that is, the influence of the price sensitivity on the product's level of greenness becomes much weaker in environments with higher level of uncertainty.

From Proposition 1, we can further obtain Corollary 1, where the effects of the degrees of risk aversion for the both retailer and manufacturer on the equilibrium results and expected demand are investigated. Here, we use $E\left(\widetilde{D}^{i *}\right)$ to represent the expected demand under $i$ supply chain power structure, where $i=m, r, v$ denote the MS, RS, and VN power structures, respectively.

\section{Corollary 1}

(a) $\partial e^{m *} / \partial \lambda_{m}<0, \quad \partial w^{m *} / \partial \lambda_{m}<0, \partial p^{m *} / \partial \lambda_{m}<0, \quad \partial e^{m *} /$ $\partial \lambda_{r}>0$, and $\partial w^{m *} / \partial \lambda_{r}>0$ if $h<h_{1}, \partial p^{m *} / \partial \lambda_{r}>0$, otherwise, $\partial p^{m *} / \partial \lambda_{r} \leq 0, \quad$ where $h_{1}=\left(A \beta^{2}\right.$ $\left(2 A b+A \lambda_{m} \sigma^{2}+2 b \lambda_{m} \sigma^{2}\right) / 2\left[b^{2} \lambda_{m}^{2} \sigma^{4}+2 A b \lambda_{m} \sigma^{2}(b+\right.$ $\left.\left.\left.\lambda_{m} \sigma^{2}\right)+A^{2}\left(2 b^{2}+2 b \lambda_{m} \sigma^{2}+\lambda_{m}^{2} \sigma^{4}\right)\right]\right)$

(b) If $h \leq\left(\beta^{2}\left(b+\lambda_{r} \sigma^{2}\right) / 2 b\left(2 b+\lambda_{r} \sigma^{2}\right)\right), \quad \partial E\left(\widetilde{D}^{m *}\right) / \partial \lambda_{m}$ $\leq 0$, otherwise, $\partial E\left(\widetilde{D}^{m *}\right) / \partial \lambda_{m}>0 ; \partial E\left(\widetilde{D}^{m *}\right) / \partial \lambda_{r}>0$

The insights from Corollary 1 are as follows. The manufacturer with higher degree of risk aversion $\left(\lambda_{m}\right)$ 
prefers to provide a lower wholesale price due to a larger risk-related cost, which further leads to a lower level of product greenness. Hence, the retailer decreases the retail price. These results are different from those presented in Xie et al. [49], which numerically show that the quality and the retail price both increase as the risk aversion of the manufacturer increases. However, in their paper, the wholesale price is assumed to be exogenous.

Corollary 1 (a) also reveals that whether the retail price would increase with the retailer's risk aversion depends on the green technology investment coefficient $(h)$, which is different from Choi et al. [48]. Without considering green technology investment, they show the retail price decreases when the retailer is more risk averse. More specifically, Corollary 1 (a) shows that the retail price decreases when the retailer's risk aversion increases only when the green technology investment coefficient is above a certain threshold, which can be explained in the following manner. On the one hand, the retailer would like to undercut the retail price as risk aversion increases. On the other hand, the level of greenness increases as the retailer's risk aversion increases, which further leads to larger demand. The retailer then prefers to increase price to get larger profit. When the investment coefficient is sufficiently high, the investment for the manufacturer is larger. At this point, the impact of the risk cost outweighs the impact of green investment; therefore, the retail price decreases as the retailer's risk aversion increases. In addition, the expected demand will increase when the retailer is more risk averse. 1 (a).

The explanation of Corollary 1 (b) is similar to Corollary

4.2. Retailer Stackelberg (RS) Model. Denoting the marginal profit of the retailer as $m, m=p-w$, the random profit of the retailer can be expressed as $\tilde{\pi}_{r}^{r}(m, w, e)=m[\widetilde{a}-b$ $(m+w)+\beta e]$, while the random profit of the manufacturer is $\widetilde{\pi}_{m}^{r}(m, w, e)=(w-c)[\widetilde{a}-b(m+w)+\beta e]-h e^{2}$.

The expected utility for the retailer is expressed as

$$
\begin{aligned}
u_{r}^{r}(m, w, e) & =E\left(\widetilde{\pi}_{r}^{r}\right)-\frac{\lambda_{r}}{2} \operatorname{Var}\left(\tilde{\pi}_{r}^{r}\right) \\
& =m[\bar{a}-b(m+w)+\beta e]-\frac{\lambda_{r}}{2} m^{2} \sigma^{2},
\end{aligned}
$$

while the manufacturer's utility is

$$
\begin{aligned}
u_{m}^{r}(m, w, e)= & E\left(\tilde{\pi}_{m}^{r}\right)-\frac{\lambda_{m}}{2} \operatorname{Var}\left(\tilde{\pi}_{m}^{r}\right) \\
= & (w-c)[\bar{a}-b(w+m)+\beta e]-h e^{2} \\
& -\frac{\lambda_{m}}{2}(w-c)^{2} \sigma^{2} .
\end{aligned}
$$

The subgame perfect Nash equilibrium is summarized in Proposition 2.

Proposition 2. The optimal greenness level and the wholesale price can be expressed as $e^{r *}=((\bar{a}-b c) \beta[B-2 b h(b+$ $\left.\left.\left.\lambda_{m} \sigma^{2}\right)\right] / B\left(4 b h-\beta^{2}+2 h \lambda_{m} \sigma^{2}\right)\right)$ and $w^{r *}=(2(\bar{a}-b c) h[B-$ $\left.\left.2 b h\left(b+\lambda_{m} \sigma^{2}\right)\right] / B\left(4 b h-\beta^{2}+2 h \lambda_{m} \sigma^{2}\right)\right)+c$, and the optimal retail price is $p^{r *}=\left(2(\bar{a}-b c) h\left[B+\left(b+\lambda_{m} \sigma^{2}\right)\left(2 b h-\beta^{2}+\right.\right.\right.$ $\left.\left.\left.2 h \lambda_{m} \sigma^{2}\right)\right] / B\left(4 b h-\beta^{2}+2 h \lambda_{m} \sigma^{2}\right)\right)+c$, where $B=4 b^{2} h+$ $4 b h\left(\lambda_{m}+\lambda_{r}\right) \sigma^{2}+\lambda_{r} \sigma^{2}\left(2 h \lambda_{m} \sigma^{2}-\beta^{2}\right)$.

Inserting $e^{r *}, w^{r *}$, and $p^{r *}$ into equations (5) and (6), the equilibrium utilities for both the manufacturer and the retailer can be obtained as equations (7) and (8):

$$
\begin{aligned}
& u_{r}^{r *}=\frac{2(\bar{a}-b c)^{2} h^{2}\left(b+\lambda_{m} \sigma^{2}\right)^{2}}{B\left(4 b h+2 h \lambda_{m} \sigma^{2}-\beta^{2}\right)}, \\
& u_{m}^{r *}=\frac{(\bar{a}-b c)^{2} h\left[B-2 b h\left(b+\lambda_{m} \sigma^{2}\right)\right]^{2}}{\left(4 b h+2 h \lambda_{m} \sigma^{2}-\beta^{2}\right) B^{2}} .
\end{aligned}
$$

From Proposition 2, Corollary 2 can be obtained.

\section{Corollary 2}

(a) $\partial e^{r *} / \partial \lambda_{m}<0, \partial w^{r *} / \partial \lambda_{m}<0, \partial p^{r *} / \partial \lambda_{m}<0, \partial e^{r *} / \partial \lambda_{r}>$ 0 , and $\partial w^{r *} / \partial \lambda_{r}>0$; if $h<\left(\beta^{2} / 2\left(b+\lambda_{m} \sigma^{2}\right)\right)$, $\partial p^{m *} / \partial \lambda_{r}>0$, otherwise, $\partial p^{m *} / \partial \lambda_{r} \leq 0$

(b) If $h \leq \beta^{2} /(2 b) \partial E\left(\widetilde{D}^{r *}\right) / \partial \lambda_{m} \leq 0$, otherwise, $\partial E\left(\widetilde{D}^{r *}\right) /$ $\partial \lambda_{m}>0 ; \partial E\left(\widetilde{D}^{r *}\right) / \partial \lambda_{r}>0$

The results in Corollary 2 are similar to those in Corollary 1 . The effects of other parameters on the equilibrium greenness level and prices are examined as they are in the MS power structure, and the results are similar.

4.3. Vertical Nash (VN) Model. Under the vertical Nash model, the manufacturer and the retailer make their decisions simultaneously. The expressions of utility functions for the two players are the same with the RS condition, i.e., $u_{r}^{r}(m, e, w)=u_{r}^{v}(m, e, w)$ and $u_{m}^{r}(m, w, e)=u_{m}^{v}(m, w, e)$. The equilibrium results are summarized in Proposition 3.

Proposition 3. The optimal greenness level and the wholesale price can be expressed as $e^{\nu *}=\left((\bar{a}-b c) \beta\left(b+\lambda_{r} \sigma^{2}\right) / 6 b^{2} h+\right.$ $\left.\lambda_{r} \sigma^{2}\left[2 h \lambda_{m} \sigma^{2}-\beta^{2}\right]+b\left[4 h\left(\lambda_{m}+\lambda_{r}\right) \sigma^{2}-\beta^{2}\right]\right)$ and $w^{v *}=$ $\left(2(\bar{a}-b c) h\left(b+\lambda_{r} \sigma^{2}\right) / 6 b^{2} h+\lambda_{r} \sigma^{2}\left[2 h \lambda_{m} \sigma^{2}-\beta^{2}\right]+b\left[4 h\left(\lambda_{m}\right.\right.\right.$ $\left.\left.\left.+\lambda_{r}\right) \sigma^{2}-\beta^{2}\right]\right)+c$, and the optimal retail price is $p^{\nu *}=(2(\bar{a}-$ $b c) h\left[2 b+\left(\lambda_{m}+\lambda_{r}\right) \sigma^{2}\right] / 6 b^{2} h+\lambda_{r} \sigma^{2}\left[2 h \lambda_{m} \sigma^{2}-\beta^{2}\right]+b[4 h$ $\left.\left.\left(\lambda_{m}+\lambda_{r}\right) \sigma^{2}-\beta^{2}\right]\right)+c$.

Furthermore, the equilibrium utility for both the manufacturer and the retailer can be given as equations (9) and (10):

$$
u_{r}^{v *}=\frac{2(\bar{a}-b c)^{2} h^{2}\left(b+\lambda_{m} \sigma^{2}\right)^{2}\left(2 b+\lambda_{r} \sigma^{2}\right)}{\left\{6 b^{2} h+\lambda_{r} \sigma^{2}\left[2 h \lambda_{m} \sigma^{2}-\beta^{2}\right]+b\left[4 h\left(\lambda_{m}+\lambda_{r}\right) \sigma^{2}-\beta^{2}\right]\right\}^{2}},
$$

$$
u_{m}^{v *}=\frac{(\bar{a}-b c)^{2} h\left(4 b h-\beta^{2}+2 h \lambda_{m} \sigma^{2}\right)\left(b+\lambda_{r} \sigma^{2}\right)^{2}}{\left\{6 b^{2} h+\lambda_{r} \sigma^{2}\left[2 h \lambda_{m} \sigma^{2}-\beta^{2}\right]+b\left[4 h\left(\lambda_{m}+\lambda_{r}\right) \sigma^{2}-\beta^{2}\right]\right\}^{2}} .
$$

From Proposition 3, Corollary 3 can be further obtained. 


\section{Corollary 3}

(a) $\partial e^{v *} / \partial \lambda_{m}<0, \partial w^{v *} / \partial \lambda_{m}<0, \partial p^{v *} / \partial \lambda_{m}<0, \partial e^{v *} / \partial \lambda_{r}>$ 0 , and $\partial w^{v *} / \partial \lambda_{r}>0$; if $h \leq\left(\beta^{2} / 2\left(b+\lambda_{m} \sigma^{2}\right)\right)$, $\partial p^{v *} / \partial \lambda_{r} \geq 0$, otherwise, $\partial p^{\nu *} / \partial \lambda_{r}<0$

(b) If $h \leq \beta^{2} /(2 b), \partial E\left(\widetilde{D}^{v *}\right) / \partial \lambda_{m} \leq 0$, otherwise, $\partial E\left(\widetilde{D}^{v *}\right) /$ $\partial \lambda_{m}>0 ; \partial E\left(\widetilde{D}^{\nu *}\right) / \partial \lambda_{r}>0$

Corollary 3 shows the results that are similar to those in Corollaries 1 and 2. The effects of other parameters on the equilibrium greenness level and prices are also similar to the MS and RS power structures.

It can be easily proved that condition in Corollaries 2 (a) and 3 (a) is larger than that in Corollary 1 (a). That is, when $h \in\left(h_{1},\left(\beta^{2} / 2\left(b+\lambda_{m} \sigma^{2}\right)\right)\right)$, if the retailer has more riskaverse, the retail prices increase in the $\mathrm{VN}$ and $\mathrm{RS}$ power structures while in the MS power structure the retail price decreases. In other words, in the VN and RS power structures the impact of the retailer risk aversion on the retail price can be easily changed by the green technology investment than the one in the MS power structure. Similarly, relationship between conditions in Corollaries 1 (b)-3 (b) can be found.

From the optimal utilities of the players, which are presented in equations (3), (4), and (7)-(10), Corollaries 4 and 5 can be further obtained. Corollary 4 shows the impact of the manufacturer's risk aversion on the equilibrium utilities of both the retailer and the manufacturer in three power structures, separately.

\section{Corollary 4}

(a) $\partial u_{m}^{m *} / \partial \lambda_{m}<0$ and $\partial u_{m}^{r *} / \partial \lambda_{m}<0$; if $h \leq\left(\beta^{2}(3 b+\right.$ $\left.\left.\lambda_{r} \sigma^{2}\right) / 2\left[5 b^{2}+2 b\left(\lambda_{m}+\lambda_{r}\right) \sigma^{2}+\lambda_{m} \lambda_{r} \sigma^{4}\right]\right), \quad \partial u_{m}^{v *} / \partial \lambda_{m}$ $\geq 0$, otherwise, $\partial u_{m}^{v *} / \partial \lambda_{m}<0$

(b) If $h<\left(\beta^{2}\left(b+\lambda_{r} \sigma^{2}\right) / 2 b\left(2 b+\lambda_{r} \sigma^{2}\right)\right)$ and $\partial u_{r}^{m *} /$ $\partial \lambda_{m} \leq 0$, otherwise, $\partial u_{r}^{m *} / \partial \lambda_{m}>0$; if $h \leq \beta^{2} /(2 b)$, $\partial u_{r}^{r *} / \partial \lambda_{m} \leq 0$ and $\partial u_{r}^{v *} / \partial \lambda_{m} \leq 0, \quad$ otherwise, $\partial u_{r}^{r *} / \partial \lambda_{m}>0$ and $\partial u_{r}^{v *} / \partial \lambda_{m}>0$

In view of Corollary 4 (a), in the MS and RS power structures, the manufacturer with lower degree of risk-averse can always achieve a higher utility. However, under the VN case results can be different. The manufacturer with higher risk aversion can also achieve a higher utility when the green technology investment coefficient is lower than a certain threshold. According to Corollaries 1-3, the greenness level, the wholesale price, and the retail price all decrease when the manufacturer is more risk-averse regardless of the power structure. That is, with a sufficiently low green technology investment coefficient, the greater degree of risk aversion yields a greater reduction in green technology investment reduction.

From Corollary 4 (b), if the green technology investment coefficient of the manufacturer is sufficiently low, the retailer can reap the higher utility when buying the product from a manufacturer with a lower degree of risk aversion. Though the retail price, wholesale price, and level of greenness all increase when the manufacturer is less risk-averse, the combined effect of the equilibrium results on demand size, marginal profit, and risk-related cost for the retailer is dependent on the green technology investment coefficient.

Corollary 5 shows the impact of the retailer's risk aversion on the equilibrium utilities of both the retailer and the manufacturer under three power structures.

\section{Corollary 5}

(a) $\partial u_{m}^{m *} / \partial \lambda_{r}>0, \partial u_{m}^{r *} / \partial \lambda_{r}>0$, and $\partial u_{m}^{v *} / \partial \lambda_{r}>0$

(b) If $h>C_{1} / C_{2}, \partial u_{r}^{m *} / \partial \lambda_{r}<0$, otherwise, $\partial u_{r}^{m *} / \partial \lambda_{r} \geq 0$, where $\quad C_{1}=3 b^{4} \beta^{2}+b^{3} \beta^{2}\left(10 \lambda_{m}+7 \lambda_{r}\right) \sigma^{2}+b^{2} \beta^{2} \lambda_{r}$ $\left(17 \lambda_{m}+5 \lambda_{r}\right) \sigma^{4}+b \beta^{2} \lambda_{r}^{2}\left(8 \lambda_{m}+\lambda_{r}\right) \sigma^{6}+\beta^{2} \lambda_{m} \lambda_{r}^{3} \sigma^{8}$ and $C_{2}=8 b^{5}+20 b^{4}\left(2 \lambda_{m}+\lambda_{r}\right) \sigma^{2}+16 b^{3}\left(\lambda_{m}^{2}+4 \lambda_{m}\right.$ $\left.\lambda_{r}+\lambda_{r}^{2}\right) \sigma^{4}+2 b^{2} \lambda_{r}\left(12 \lambda_{m}^{2}+17 \lambda_{m} \lambda_{r}+2 \lambda_{r}^{2}\right) \sigma^{6}+6 b \lambda_{m}$ $\lambda_{r}^{2}\left(2 \lambda_{m}+\lambda_{r}\right) \sigma^{8}+2 \lambda_{m}^{2} \lambda_{r}^{3} \sigma^{10} ; \quad \partial u_{r}^{r *} / \partial \lambda_{r}<0 ; \quad$ if $h>\left(\beta^{2}\left(3 b+\lambda_{r} \sigma^{2}\right) / 2\left(5 b^{2}+2 b\left(\lambda_{m}+\lambda_{r}\right) \sigma^{2}+\lambda_{m} \lambda_{r} \sigma^{4}\right)\right)$, $\partial u_{r}^{v *} / \partial \lambda_{r}<0$, otherwise, $\partial u_{r}^{v *} / \partial \lambda_{r} \geq 0$

Corollary 5 (a) shows that, in every power structure, choosing a retailer with a higher level of risk aversion can benefit the manufacturer because the manufacturer can get a higher marginal cost while also providing a product with a higher level of greenness. In other words, a higher expected profit due to the higher risk aversion of a retailer can compensate the increased green technology investment and riskrelated cost. Corollary 5 (b) indicates that, for RS power structure, the utility of the retailer decreases with his risk aversion, while in $\mathrm{VN}$ and MS power structures, the impact of the retailer's risk aversion on his own utilities depends on the green technology investment coefficient.

\section{Discussion}

5.1. Analytical Comparison. Proposition 4 summarizes the outcomes by comparing the equilibrium results in the MS, $\mathrm{RS}$, and VN power structures.

\section{Proposition 4}

(a) If $h \geq \beta^{2} /(2 b), m^{\nu *} \leq m^{r *}$

(b) If $h \geq \beta^{2} /(2 b), \quad e^{v *} \geq e^{r *}>e^{m *}$, otherwise, $e^{r *}>$ $e^{v *}>e^{m *}$

(c) If $h \geq \beta^{2} /(2 b), \quad w^{m *}>w^{v *} \geq w^{r *}$; if $\beta^{2}\left(b+\lambda_{r} \sigma^{2}\right) /$ $2 b\left(2 b+\lambda_{r} \sigma^{2}\right)<h<\left(\beta^{2} /(2 b)\right), w^{m *}>w^{v *}$ and $w^{r *}>$ $w^{v *} ; \quad$ if $h \leq\left(\beta^{2}\left(b+\lambda_{r} \sigma^{2}\right) / 2 b\left(2 b+\quad \lambda_{r} \sigma^{2}\right)\right), w^{m *} \leq$ $w^{v *}<w^{r *}$

(d) If $h \geq\left(\beta^{2}\left[b+\left(\lambda_{m}+\lambda_{r}\right) \sigma^{2}\right] / 2 b\left(b+\lambda_{r} \sigma^{2}\right)\right), p^{m *} \geq p^{v *}$ and $p^{r *} \geq p^{v *}$; if $h \leq \beta^{2} /\left(2\left(b+\lambda_{m} \sigma^{2}\right)\right)$ or $\beta^{2} /$ $(2 b)<h<\left(\beta^{2}\left[b+\left(\lambda_{m}+\lambda_{r}\right) \sigma^{2}\right] / 2 b\left(b+\lambda_{r} \sigma^{2}\right)\right), \quad p^{m *}$ $<p^{v *}<p^{r *} ; \quad$ if $\quad \beta^{2} /\left(2\left(b+\lambda_{m} \sigma^{2}\right)\right)<h \leq \beta^{2} /(2 b)$, $p^{v *}>p^{m *}$ and $p^{v *}>p^{r *}$

From 4 (a), we can find that when the technology investment coefficient is lower than $\beta^{2} /(2 b)$, the retailer sets a lower marginal profit with channel power. That is, the impact of channel leadership on the retailer's marginal profit can be changed by the technology investment coefficient. 
Proposition 4 (b) indicates that a product's level of greenness is always the lowest in a MS power structure, which means that a manufacturer with power prefers to set a favorable level of greenness level to pursue economic interest. However, whether the greenness level is higher in the $\mathrm{VN}$ power structure compared with that in the RM power structure depends on the technology investment efficiency. More specifically, in the VN scenario the level of product greenness is higher when the technology investment coefficient is higher than $\beta^{2} /(2 b)$. Otherwise, the product's level of greenness is higher under an RS power structure. Based on the response function of the manufacturer, the greenness level relies on the marginal profit. Thus, the greenness level is lower in $\mathrm{RS}$ power structure than that in the $\mathrm{VN}$ power structure when $m^{\nu *} \leq m^{r *}$. This result is different from those reported in the literature. Xie et al. [49] and Chen et al. [38] show the level of greenness or quality is always the highest in $\mathrm{VN}$ power structure. Similarly, we have the wholesale is lower in RS power structure than that in the VN power structure when $m^{\nu *} \leq m^{r *}$

Proposition 4 (c) shows that the impact of power structure on the wholesale price depends on the technology investment coefficient. More specifically, only when the technology investment coefficient is higher than $\beta^{2} /(2 b)$ will the manufacturer provide the highest wholesale price under the MS scenario. If the technology investment coefficient is lower than $\beta^{2}\left(b+\lambda_{r} \sigma^{2}\right) /\left[2 b\left(2 b+\lambda_{r} \sigma^{2}\right)\right]$, the manufacturer can only set the lowest wholesale price under the MS scenario.

When the technology investment coefficient is sufficiently high $\left(\beta^{2} /(2 b)\right)$, the retail price in the $\mathrm{VN}$ power structure is lower than that in the RS structure. Because under this condition, the impact of power structure on the retailer's marginal profit is larger than that on the manufacturer's wholesale price. Also, when the technology investment coefficient is intermediate $\left[\left(\beta^{2} /\left(2\left(b+\lambda_{m} \sigma^{2}\right)\right)\right), \beta^{2} /(2 b)\right]$, the retail price in the $\mathrm{VN}$ power structure is higher than that in the RS structure for the same reason. However, when the green technology investment coefficient is below a threshold $\left(h \leq \beta^{2} /\left(2\left(b+\lambda_{m} \sigma^{2}\right)\right)\right)$, the impact of power structure on the manufacturer's wholesale price is larger than that on the retailer's marginal profit. Furthermore, when the technology investment coefficient is higher than $\beta^{2} /(2 b)$, the retail price in the MS structure can be the lowest even when the wholesale price is the highest. That is for the retailer, who can set higher marginal profit with channel power under RS structure.

Proposition 4 indicates that if the technology investment coefficient is above a certain threshold $\left(h \geq\left(\beta^{2}\left[b+\left(\lambda_{m}+\lambda_{r}\right) \sigma^{2}\right] / 2 b\left(b+\lambda_{r} \sigma^{2}\right)\right)\right)$, consumers can achieve the highest level of greenness with the lowest retail price in a more balanced supply chain. If the green technology investment coefficient is sufficiently low $\left(h \leq \beta^{2} /\left(2\left(b+\lambda_{m} \sigma^{2}\right)\right)\right)$, consumers will pay the highest price for the product with the highest level of greenness in the RS power structure.

To compare the utilities of the participants under different power structures, the following proposition is derived.

\section{Proposition 5}

$$
\begin{aligned}
& \text { (a) } u_{r}^{r *} \geq u_{r}^{v *}>u_{r}^{m *} \\
& \text { (b) } u_{m}^{m *} \geq u_{m}^{v *} \text {; if } h \geq\left(\beta^{2} /(2 b)\right), u_{m}^{v *} \geq u_{m}^{r *} \text {, otherwise, } \\
& u_{m}^{v *}<u_{m}^{r *} \\
& \text { (c) } u_{c}^{v *}>u_{c}^{m *}, \quad \text { where } \quad u_{c}^{v *}=u_{r}^{v *}+u_{m}^{v *} \quad \text { and } \\
& u_{c}^{m *}=u_{r}^{m *}+u_{m}^{m *}
\end{aligned}
$$

Proposition 5 (a) shows that the retailer achieves the highest utility in the RS power structure, while the lowest utility is achieved if the manufacturer is significantly powerful in the supply chain. This means that even when the risk aversions of the players are considered, the retailer can also use his power to achieve greater utility. Proposition 5 (b) only theoretically proved that risk-averse manufacturers can use their power to achieve a higher utility than in the VN power structure. To determine whether the channel leadership can guarantee a higher utility compared to the retailer-dominant supply chain, it is further investigated through numerical analysis. In addition, Proposition 5 (c) reveals that a more balanced environment benefits the entire supply chain compared to a manufacturer-led supply chain.

5.2. Numerical Examples. From Propositions 4 and 5, we know that it is difficult to compare all the optimal results under different power structures analytically. To better understand the economic and environmental performance of supply chains under three different power structures, we numerically compare the price decisions and utilities of supply chain participants under these three structures. Also, some managerial implications can be obtained to provide suggestion for decision makers when choosing supply chain partner and investing in green technology. Specifically, we study the effect of price sensitivity $b$ on the wholesale price. As the impact of power structures on the optimal retail price is small, we omit it. Instead, we compare the expected demands under different power structures. Moreover, we study the impact of the green technology investment coefficient on the overall utility of the supply chain and the manufacturer's utility under different power structures. We also explore the impact of the greenness level sensitivity on the utility of the manufacturer as consumers' environmental awareness is one of the most important motivations for manufacturer to invest in green technology.

To better understand the impact of the price sensitivity and power structure on the wholesale price, as depicted in Figure 3, we change $b$ from 0.6 to 2 , while the values of other parameters used are $\bar{a}=10, \lambda_{m}=1, \lambda_{r}=1.5, \beta=1.5, c=1$, $h=1$, and $\sigma=0.5$. The assumption $h>\left(\beta^{2} / 2\left(2 b+\lambda_{m} \sigma^{2}\right)\right)$ is satisfied.

Figure 3 indicates that the level of greenness decreases as the price sensitivity decreases. When price sensitivity decreases, the retailer prefers to provide a low priced product to attract consumers. Since a product's level of greenness is closely related to the green technology investment, the manufacturer decreases the greenness level to further decrease his cost. Moreover, as a supplement to Proposition 4, Figure 3 shows that when the technology investment 


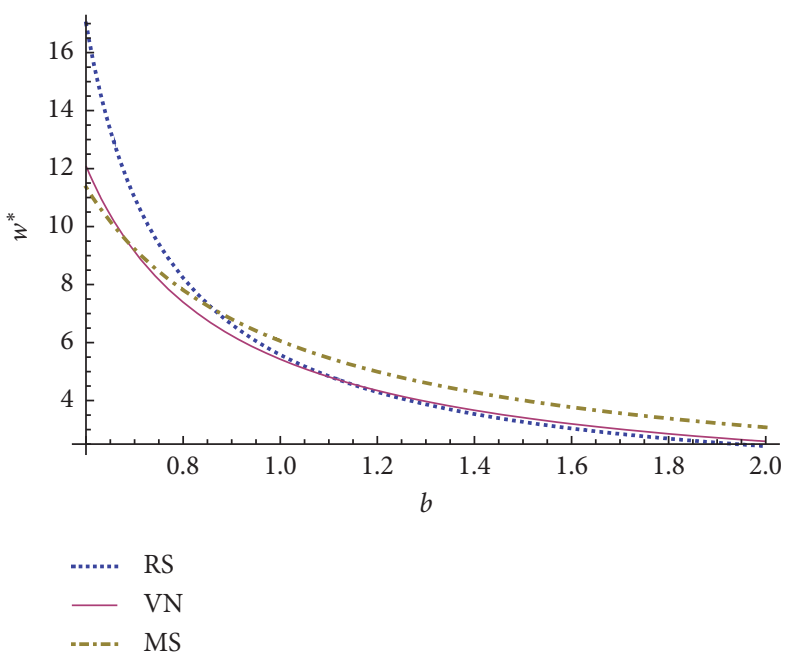

FIgURE 3: The wholesale price versus price sensitivity.

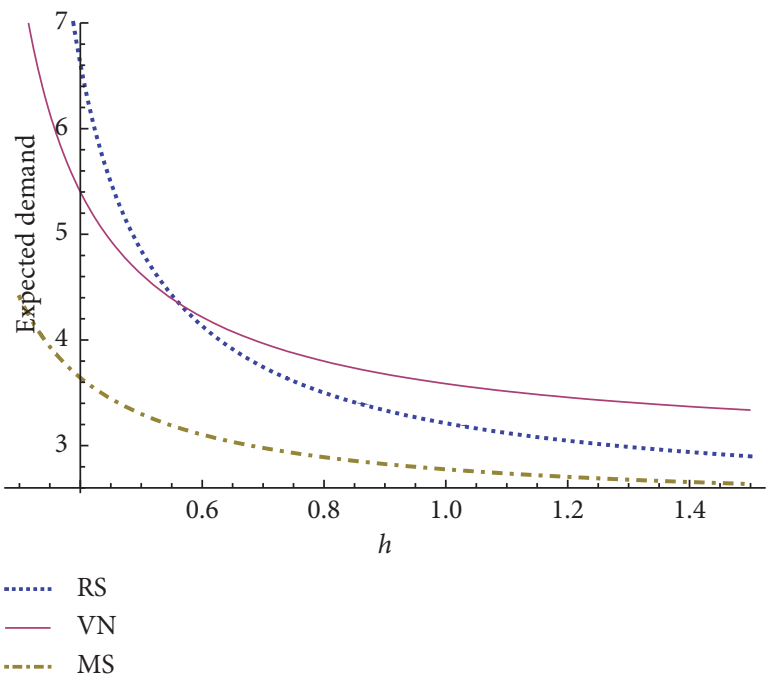

FIGURE 4: Effects of the green technology investment coefficient on the expected demand.

coefficient is intermediate, whether the wholesale price in RS structure is higher than that in the MS power structure depends on the price sensitivity. That is, the impact of power structure on the wholesale price can be offset by the technology investment coefficient.

Figure 4 shows the impact of risk aversion on the expected demand $E\left(\widetilde{D}^{i *}\right)=\bar{a}-b p^{i *}+\beta e^{i *}$ under different power structures. We change the manufacturer's risk aversion from 0 to 2 , and the values of other parameters are the same with Figure 3 and $b=2$.

Figure 4 shows that the expected demand decreases as the green technology investment coefficient increases. From sensitivity analysis after Proposition 1, we know that both the greenness level and retail price decrease with the green technology investment coefficient. Even though the demand is more sensitive to the price than to the greenness level ( $b=2$ and $\beta=1.5$ ), the expected demand decreases as the green technology investment coefficient increases. That is,

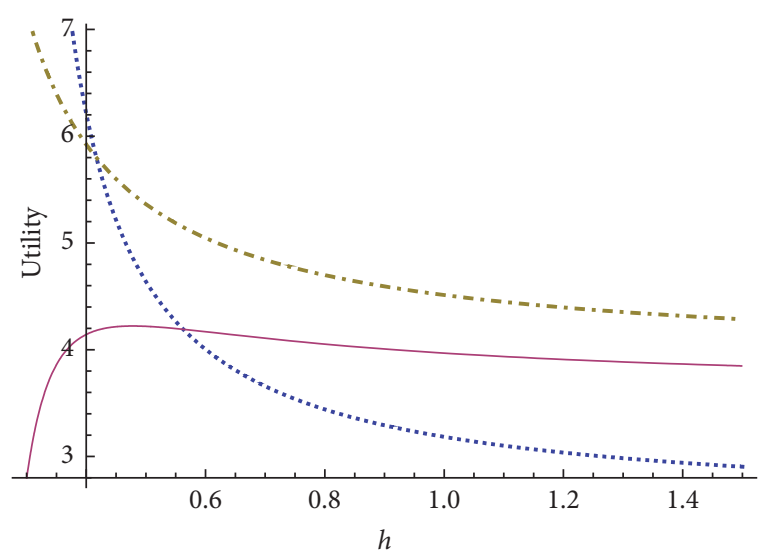

$\begin{array}{ll}\ldots \ldots & \text { RS } \\ -\quad & \text { VN } \\ \ldots= & \text { MS }\end{array}$

FIGURE 5: Effects of the green technology investment coefficient on the manufacturers' utility.

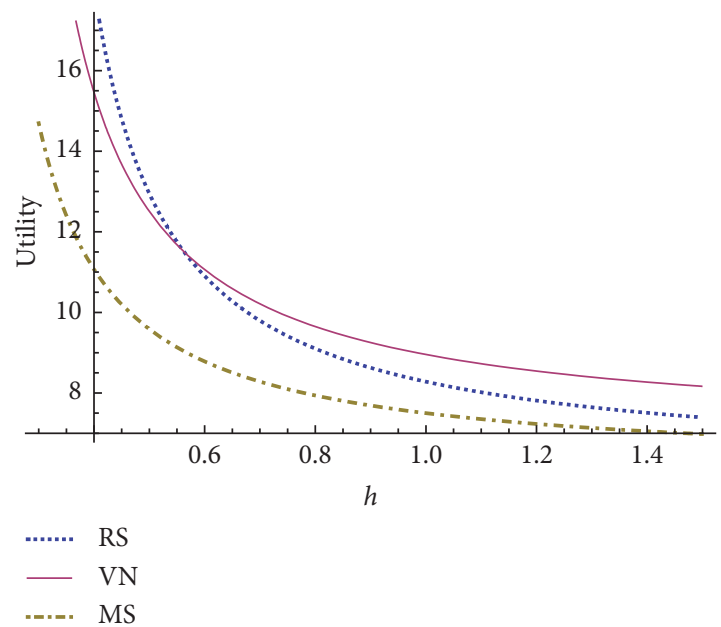

FIGURE 6: Effects of the green technology investment coefficient on total utility of the supply chain.

the retail price compared with the greenness level is less sensitive to changes in green technology investment coefficient. Moreover, the expected demand is smallest in the MS supply chain among all the supply chain structures as the manufacturer with channel power always set the lowest greenness level.

To explore the impact of power structures on the utilities of the manufacturer and the whole supply chain, we depict Figures 5-7. The values of parameters used are the same with those used in Figure 3. In Figures 5 and 6, we change the green technology investment coefficient from 0.3 to 1.5 . The assumption $h>\left(\beta^{2} / 2\left(2 b+\lambda_{m} \sigma^{2}\right)\right)$ is satisfied.

Figure 5 illustrates that when the risk aversions of the participants are considered, the impact of the power structure on the optimal utilities can be different, which means that the channel leadership is not a necessary condition for the risk-averse manufacturer to achieve a higher utility. More specifically, Figure 5 shows that there is a 


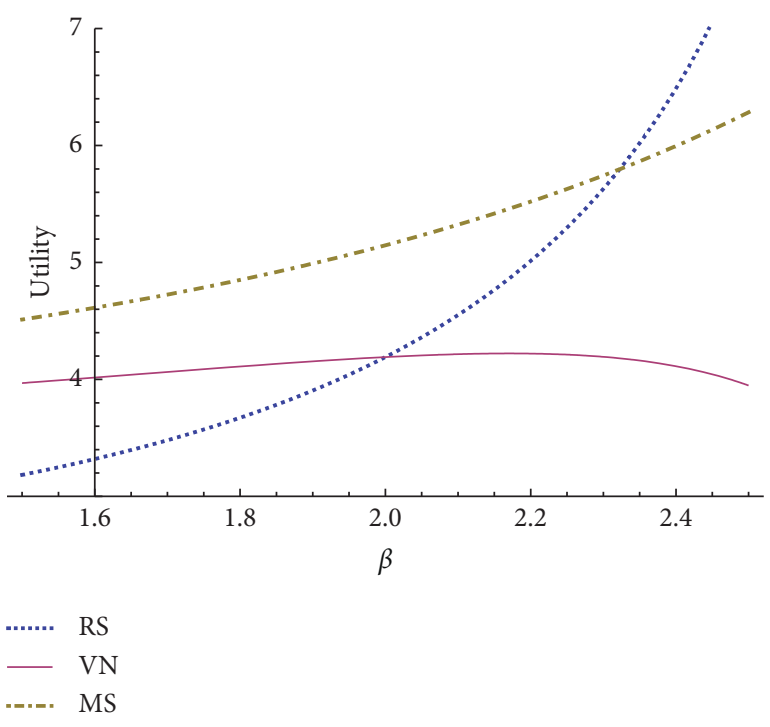

FIGURE 7: Effects of the greenness level sensitivity on the utilities of the manufacturer.

threshold below which the RS power structure is the best choice for the manufacturer. From Proposition 4 and Figure 4, we know that when the green technology investment coefficient is sufficiently low, the level of product greenness, retail price, wholesale price, and expected demand are all the highest in the RS power structure. Hence, the manufacturer's utility is highest in RS as the higher expected profit covers the higher investment and the risk-related costs. Figure 6 also confirms that the total utility of the supply chain is highest in the RS power structure when the green technology coefficient is below a threshold. However, when the green technology coefficient is high enough, the balanced supply chain is favorable to all the participants.

Proposition 5 and Figures 5 and 6 reveal some managerial insights regarding which the channel structure is beneficial to the players. When the green technology is comparatively cheap, both the retailer and the manufacturer can achieve the highest utility and consumers can also obtain a product with the highest level of greenness in a retailerdominant supply chain. However, if the green technology coefficient is particularly high, the retailer can benefit from an RS power structure, while the manufacturer can gain more utility in the MS power structure.

To investigate the impact of the greenness level sensitivity on the manufacturer's utility, we numerically compare the utilities of the manufactures under three power structures. We change the greenness level sensitivity from 1.5 to 2.5.

Figure 7 shows that, in the VN power structure, the manufacturer's utility first increases and then decreases with the greenness level sensitivity. However, in the MS and RS power structures, the manufacturers' utilities increase as the greenness level sensitivity increases. Moreover, when the demand-enhancing effectiveness of the greenness level is relatively high, the differences between each power structure increase. In other words, choosing a retailer-dominant power structure can be the wisest choice for the manufacturer when the consumers are sensitive to the level of product greenness.

\section{Conclusions}

In this paper, the impact of risk-averse behaviors and power structures of supply chain participants on product's level of greenness and prices decisions is investigated with uncertain demand. Unlike Chen et al. [38], we assume the supply chain players are risk averse. To evaluate the random profits of the supply chain players, we use the mean-variance method to obtain the utility functions. In the game models, the manufacturer determines the product's level of greenness and the wholesale price, while the retailer decides the retail price under three different power structures, i.e., manufacturer Stackelberg (MS), retailer Stackelberg (RS), and vertical Nash (VN). Some results are obtained by discussing and comparing the equilibrium results under these three power structures together with numerical analysis. The main management insights are as follows.

Economically, when considering supply chain players' risk-averse behaviors under uncertain circumstance, a retailer can still get the highest utility out of its channel power. However, to the manufacturer, things may be different. The small manufacturer under MS supply chain can still achieve the largest utility compared with under other two power structures when consumers are notably sensitive to the level of greenness, or when the green technology investment cost is comparatively low. Moreover, when the green technology investment coefficient is sufficiently low, the economic and environmental performance of the supply chain may be best in the RS model, where both the manufacturer and the retailer is possible to get the highest utilities, while consumers can obtain product with the highest level of greenness.

The level of product greenness and the utilities of players rely heavily on the participants' risk aversions. Regardless of the power structure, it is beneficial for a manufacturer with higher degree of risk aversion to decrease the level of product greenness. Furthermore, the manufacturer should invest more in green product design when the risk aversion of the retailer increases.

In the case of environmental performance, whether a manufacturer will offer the highest level of product greenness in the VN model relative to the MS and RS scenarios depends on the green technology investment coefficient. The manufacturer can obtain the optimal utility while providing the best environmental performance product in the $\mathrm{VN}$ scenario when the green technology investment coefficient is large enough. Moreover, in a manufacture dominant supply chain, consumers can obtain the cheapest product with the lowest level of product greenness if the green technology is comparatively cheap.

There are still several research directions for future work. First, to obtain more elegant analytical results, a linear 
additive demand with a stochastic market base is used in this study. The impact of different types of demand on the key results should be explored. In addition, only one type of product is considered in the paper, while competition among different products is quite common in the real world. Further research could consider the product line design problems or competition between different manufacturers in the modeling. Finally, a two-echelon supply chain consisting of a retailer and a manufacturer is considered in this research. Further research could also consider horizontal or vertical competition to investigate the spillover effect on sustainable supply chain performance.

\section{Appendix}

Proof of Proposition 1. From equation (1), $\left(\partial^{2} u_{r}^{m} / \partial p^{2}\right)=$ $-2 b-\lambda_{r} \sigma^{2}<0$ can be obtained, that is, $u_{r}^{m}$ is a concave function of $p$. Thus, solving the first-order condition of $u_{r}^{m}(p, w, e)$ for $p, \quad\left(\partial u_{r}^{m} / \partial p\right)=\bar{a}+e \beta-\left(2 b+\lambda_{r} \sigma^{2}\right)$ $p+\left(b+\lambda_{r} \sigma^{2}\right) w=0$, and the retail price reaction function of the retailer can be expressed as

$$
p(w, e)=\frac{(\bar{a}+e \beta+A w)}{(A+b)} .
$$

Inserting (A.1) into (2), we obtain $u_{m}^{m}(w, e)=A[(\bar{a}+$ $\operatorname{ten} \beta)-b w](w-c) /(A+b)-h e^{2}-\left(\begin{array}{ll}1 / & 2\end{array}\right)(w-c)^{2} \lambda_{m} \sigma^{2}$, where $A=b+\lambda_{r} \sigma^{2}$. The Hessian matrix over $(w, e)$ is $\left(\begin{array}{cc}-2 h & A \beta /(A+b) \\ A \beta /(A+b) & -2 A b /(A+b)-\lambda_{m} \sigma^{2}\end{array}\right)$, which is negatively defined as $h>\left(\beta^{2} / 2\left(2 b+\lambda_{m} \sigma^{2}\right)\right)>\left(A^{2} \beta^{2} / 2(A+b)[2 A b+\right.$ $\left.\left.\lambda_{m} \sigma^{2}(A+b)\right]\right)$. The optimal wholesale price $w^{m *}$ and environmental investment $e^{m *}$ can be obtained by solving the following first-order conditions:

$$
\begin{aligned}
& \frac{\partial u_{m}^{m}(w, e)}{\partial e}=-2 e h+\frac{A \beta(w-c)}{b+A}=0, \\
& \frac{\partial u_{m}^{m}(w, e)}{\partial w}=\frac{A\left[\bar{a}+b c-\left(2 b+\lambda_{m} \sigma^{2}\right) w+e \beta+c \lambda_{m} \sigma^{2}\right]-(w-c) b \lambda_{m} \sigma^{2}}{A+b}=0 .
\end{aligned}
$$

Inserting $w^{m *}$ and $e^{m *}$ into (A.1), the equilibrium retail price $p^{m *}$ can be further obtained. (a) Differentiating $e^{m *}, w^{m *}$, and $p^{m *}$ with respect to $\lambda_{m}$, we have

Proof of Corollary 1.

$$
\begin{aligned}
& \frac{\partial e^{m *}}{\partial \lambda_{m}}=-\frac{\left[2(\bar{a}-b c) h \beta\left(b+\lambda_{r} \sigma^{2}\right)^{2}\left(2 b \sigma+\lambda_{r} \sigma^{3}\right)^{2}\right]}{E^{2}}<0, \\
& \frac{\partial w^{m *}}{\partial \lambda_{m}}=-\frac{\left[4(\bar{a}-b c) h^{2} \sigma^{2}\left(b+\lambda_{r} \sigma^{2}\right)\left(2 b+\lambda_{r} \sigma^{2}\right)^{3}\right]}{E^{2}}<0, \\
& \frac{\partial p^{m *}}{\partial \lambda_{m}}=-\frac{\left[2(\bar{a}-b c) h \sigma^{2}\left(b+\lambda_{r} \sigma^{2}\right)^{2}\left(2 b+\lambda_{r} \sigma^{2}\right)\left(4 b h+\beta^{2}+2 h \lambda_{r} \sigma^{2}\right)\right]}{E^{2}}<0 .
\end{aligned}
$$

Differentiating $e^{m *}$ and $w^{m *}$ with respect to $\lambda_{r}$, we have

$$
\begin{gathered}
\frac{\partial e^{m *}}{\partial \lambda_{r}}=\frac{2 b(\bar{a}-b c) h \sigma^{2}\left[\lambda_{r}^{2} \sigma^{4}\left(\beta^{2}+2 h \lambda_{m} \sigma^{2}\right)+2 b \lambda_{r} \sigma^{2}\left(\beta^{2}+4 h \lambda_{m} \sigma^{2}\right)+b^{2}\left(\beta^{2}+8 h \lambda_{m} \sigma^{2}\right)\right]}{E^{2}}>0, \\
\frac{\partial w^{m *}}{\partial \lambda_{r}}=\frac{2 b(\bar{a}-b c) h \sigma^{2}\left[\lambda_{r}^{2} \sigma^{4}\left(\beta^{2}+2 h \lambda_{m} \sigma^{2}\right)+2 b \lambda_{r} \sigma^{2}\left(\beta^{2}+4 h \lambda_{m} \sigma^{2}\right)+b^{2}\left(\beta^{2}+8 h \lambda_{m} \sigma^{2}\right)\right]}{E^{2}}>0,
\end{gathered}
$$


where

$$
\begin{aligned}
E= & 8 b^{3} h+\lambda_{r}^{2} \sigma^{4}\left(2 h \lambda_{m} \sigma^{2}-\beta^{2}\right) \\
& +2 b \lambda_{r} \sigma^{2}\left[2 h\left(2 \lambda_{m}+\lambda_{r}\right) \sigma^{2}-\beta^{2}\right] \\
& +b^{2}\left[4 h\left(2 \lambda_{m}+3 \lambda_{r}\right) \sigma^{2}-\beta^{2}\right] .
\end{aligned}
$$

$$
\begin{aligned}
& \frac{\partial p^{m *}}{\partial \lambda_{r}}=\frac{\partial p^{m *}}{\partial A} \frac{\partial A}{\partial \lambda_{r}}, \\
& \frac{\partial p^{m *}}{\partial \lambda_{r}}=-2 h(\bar{a}-b c) \sigma^{2} \frac{\left\{\left[2 A b+\lambda_{m} \sigma^{2}(A+b)\right] 2 \lambda_{m} \sigma^{2}(b+A)+4 A^{2} b^{2}\right\} h-A \beta^{2}\left[(2 b+A) \lambda_{m} \sigma^{2}+2 A b\right]}{\left[2 b^{2} h \lambda_{m} \sigma^{2}+4 A b h\left(b+\lambda_{m} \sigma^{2}\right)+A^{2}\left(4 b h-\beta^{2}+2 h \lambda_{m} \sigma^{2}\right)\right]^{2}}
\end{aligned}
$$

thus if

$$
\begin{aligned}
h & <\frac{A \beta^{2}\left(2 A b+A \lambda_{m} \sigma^{2}+2 b \lambda_{m} \sigma^{2}\right)}{2\left[b^{2} \lambda_{m}^{2} \sigma^{4}+2 A b \lambda_{m} \sigma^{2}\left(b+\lambda_{m} \sigma^{2}\right)+A^{2}\left(2 b^{2}+2 b \lambda_{m} \sigma^{2}+\lambda_{m}^{2} \sigma^{4}\right)\right]} \\
\frac{\partial p^{m *}}{\partial \lambda_{r}}>0 &
\end{aligned}
$$

otherwise, $\left(\partial p^{m *} / \partial \lambda_{r}\right) \leq 0$.

(b) Differentiating $E\left(D^{m *}\right)$ with respect to $\lambda_{r}$, we have

$\frac{\partial E\left(D^{m *}\right)}{\partial \lambda_{r}}=\frac{2 b(\bar{a}-b c) h \sigma^{2}\left\{4 b^{4} h+8 b^{3} h\left(\lambda_{m}+\lambda_{r}\right) \sigma^{2}+\lambda_{m} \lambda_{r}^{2} \sigma^{6}\left(\beta^{2}+2 h \lambda_{m} \sigma^{2}\right)+2 b \lambda_{m} \lambda_{r} \sigma^{4}\left[\beta^{2}+2 h\left(2 \lambda_{m}+\lambda_{r}\right) \sigma^{2}\right]+b^{2}\left[\beta^{2} \lambda_{m} \sigma^{2}+4 h\left(2 \lambda_{m}^{2}+3 \lambda_{m} \lambda_{r}+\lambda_{r}^{2}\right) \sigma^{4}\right]\right\}}{E^{2}}>0$

By taking the derivation of $E\left(D^{m *}\right)$ with respect to $\lambda_{m}$, we have

$$
\frac{\partial E\left(D^{m *}\right)}{\partial \lambda_{m}}=\frac{2(\bar{a}-b c) h \sigma^{2}\left(b+\lambda_{r} \sigma^{2}\right)^{2}\left(2 b+\lambda_{r} \sigma^{2}\right)\left(4 b^{2} h-b \beta^{2}+2 b h \lambda_{r} \sigma^{2}-\beta^{2} \lambda_{r} \sigma^{2}\right)}{E^{2}}
$$

so when $h \leq\left(\beta^{2}\left(b+\lambda_{r} \sigma^{2}\right) / 2 b\left(2 b+\lambda_{r} \sigma^{2}\right)\right), \partial E\left(D^{m *}\right) / \partial \lambda_{m} \leq$ 0 , otherwise, $\partial E\left(D^{m *}\right) / \partial \lambda_{m}>0$.

Proof of Proposition 2. From equation (6), the Hessian matrix over $(w, e)$ is $\left(\begin{array}{cc}-2 b-\lambda_{m} \sigma^{2} & \beta \\ \beta & -2 h\end{array}\right)$, which is negatively defined as $h>\left(\beta^{2} / 2\left(2 b+\lambda_{m} \sigma^{2}\right)\right)$. Solving the firstorder condition of $u_{m}^{r}(w, e)$ for $(w, e)$

$$
\begin{aligned}
& \frac{\partial u_{m}^{r}(m, w, e)}{\partial w}=\bar{a}+e \beta+b(c-m-2 w)-(w-c) \lambda_{m} \sigma^{2}=0, \\
& \frac{\partial u_{m}^{r}(m, w, e)}{\partial w}=(w-c) \beta-2 e h=0,
\end{aligned}
$$

and we get the reaction function of the manufacturer: 


$$
\begin{aligned}
e(m) & =\frac{[\bar{a}-b(c+m)] \beta}{4 b h+2 h \lambda_{m} \sigma^{2}-\beta^{2}}, \\
w(m) & =\frac{2 \bar{a} h+2 c h\left(b+\lambda_{m} \sigma^{2}\right)-c \beta^{2}-2 b h m}{4 b h+2 h \lambda_{m} \sigma^{2}-\beta^{2}} .
\end{aligned}
$$

Inserting $e(m)$ and $w(m)$ into (5), there is

$$
u_{r}^{r}(m)=\frac{4 h m\left[(\bar{a}-b c)\left(b+\sigma^{2} \lambda_{m}\right)\right]-m^{2} B}{8 b h-2 \beta^{2}+4 h \lambda_{m} \sigma^{2}},
$$

where $B=4 b^{2} h+4 b h \sigma^{2}\left(\lambda_{m}+\lambda_{r}\right)+\lambda_{r} \sigma^{2}\left(2 h \lambda_{m} \sigma^{2}-\beta^{2}\right)$.

As

$$
\frac{\mathrm{d}^{2} u_{r}^{r}(m)}{\mathrm{d} m^{2}}=\frac{\beta^{2} \sigma^{2} \lambda_{r}-h\left[4 b^{2}+4 b\left(\lambda_{m}+\lambda_{r}\right) \sigma^{2}+2 \lambda_{m} \lambda_{r} \sigma^{4}\right]}{4 b h-\beta^{2}+2 h \lambda_{m} \sigma^{2}},
$$

we know if $h>\left(\lambda_{r} \sigma^{2} \beta^{2} / 4 b^{2}+4 b\left(\lambda_{m}+\lambda_{r}\right) \sigma^{2}+2 \lambda_{m} \lambda_{r} \sigma^{4}\right)$, $u_{r}^{r}(m)$ is negatively defined. Since $\left(\beta^{2} / 2(2 b+\right.$ $\left.\left.\lambda_{m} \sigma^{2}\right)\right)-\left(\lambda_{r} \sigma^{2} \beta^{2} / 4 b^{2}+4 b\left(\lambda_{m}+\lambda_{r}\right) \sigma^{2}+2 \lambda_{m} \lambda_{r} \sigma^{4}\right)>0$, the equilibrium results always exist. Solving $\left(\mathrm{d} u_{r}^{r}(m) / \mathrm{d} m\right)=0$, the optimal marginal profit $m^{r *}=2(\bar{a}-b c) h\left(b+\lambda_{m} \sigma^{2}\right) / B$ can be obtained, and furthermore, the optimal wholesale price $w^{r *}$, sustainable investment level $e^{r *}$, and retail price $p^{r *}$ can be obtained, where $p^{r *}=m^{r *}+w^{r *}$.

\section{Proof of Corollary 2}

(a) From Proposition 2, differentiating $e^{r *}$ and $w^{r *}$ with respect to $\lambda_{m}$, there are

$$
\begin{aligned}
& \frac{\partial e^{r *}}{\partial \lambda_{m}}=-2(\bar{a}-b c) h \beta \sigma^{2} \frac{B_{1} h^{2}+B_{2} h+b \beta^{4} \lambda_{r} \sigma^{2}+\beta^{4} \lambda_{r}^{2} \sigma^{4}}{\left(\beta^{2}-4 b h-2 h \lambda_{m} \sigma^{2}\right)^{2}\left[4 b^{2} h+4 b h\left(\lambda_{m}+\lambda_{r}\right) \sigma^{2}+\lambda_{r} \sigma^{2}\left(2 h \lambda_{m} \sigma^{2}-\beta^{2}\right)\right]^{2}} \\
& \frac{\partial w^{r *}}{\partial \lambda_{m}}=-4(\bar{a}-b c) h^{2} \sigma^{2} \frac{B_{1} h^{2}+B_{2} h+b \beta^{4} \lambda_{r} \sigma^{2}+\beta^{4} \lambda_{r}^{2} \sigma^{4}}{\left(\beta^{2}-4 b h-2 h \lambda_{m} \sigma^{2}\right)^{2}\left[4 b^{2} h+4 b h\left(\lambda_{m}+\lambda_{r}\right) \sigma^{2}+\lambda_{r} \sigma^{2}\left(2 h \lambda_{m} \sigma^{2}-\beta^{2}\right)\right]^{2}}
\end{aligned}
$$

As $\quad B_{1}>0$ and $B_{2}^{2}-4 B_{1}\left(b \beta^{4} \lambda_{r} \sigma^{2}+\beta^{4} \lambda_{r}^{2} \sigma^{4}\right)=$

Differentiating $p^{r *}$ with respect to $\lambda_{m}$, there is $-16 b^{2} \beta^{4} \lambda_{r} \sigma^{2}\left(b+\lambda_{m} \sigma^{2}\right)^{2}\left(2 b+\lambda_{r} \sigma^{2}\right)<0$, we obtain $\left(\partial e^{r *} / \partial \lambda_{m}\right)<0$ and $\left(\partial w^{r *} / \partial \lambda_{m}\right)<0$.

$$
\frac{\partial p^{r *}}{\partial \lambda_{m}}=-2(\bar{a}-b c) h \sigma^{2} \frac{B_{3} \lambda_{m}^{2}+B_{4} \lambda_{m}+B_{5}}{\left(\beta^{2}-4 b h-2 h \lambda_{m} \sigma^{2}\right)^{2}\left[4 b^{2} h+4 b h\left(\lambda_{m}+\lambda_{r}\right) \sigma^{2}+\lambda_{r} \sigma^{2}\left(2 h \lambda_{m} \sigma^{2}-\beta^{2}\right)\right]^{2}},
$$

as $B_{3}>0$ and $B_{4}^{2}-4 B_{3} B_{5}=-64 b^{2} \quad h^{3}(-2 b h+$ $\left.\beta^{2}\right)^{2} \lambda_{r} \sigma^{6}\left(\beta^{2}+h \lambda_{r} \sigma^{2}\right)<0,\left(\partial p^{r *} / \partial \lambda_{m}\right)<0$.
Differentiating $w^{r *}, e^{r *}$, and $p^{r *}$ with respect to $\lambda_{r}$, respectively, we obtain

$$
\begin{aligned}
& \frac{\partial w^{r *}}{\partial \lambda_{r}}=\frac{4 b(\bar{a}-b c) h^{2} \sigma^{2}\left(b+\lambda_{m} \sigma^{2}\right)}{\left[4 b^{2} h+4 b h\left(\lambda_{m}+\lambda_{r}\right) \sigma^{2}+\lambda_{r} \sigma^{2}\left(-\beta^{2}+2 h \lambda_{m} \sigma^{2}\right)\right]^{2}}>0, \\
& \frac{\partial e^{r *}}{\partial \lambda_{r}}=\frac{2 b(\bar{a}-b c) h \beta \sigma^{2}\left(b+\lambda_{m} \sigma^{2}\right)}{\left[4 b^{2} h+4 b h\left(\lambda_{m}+\lambda_{r}\right) \sigma^{2}+\lambda_{r} \sigma^{2}\left(-\beta^{2}+2 h \lambda_{m} \sigma^{2}\right)\right]^{2}}>0, \\
& \frac{\partial p^{r *}}{\partial \lambda_{r}}=-\frac{2(\bar{a}-b c) h \sigma^{2}\left(b+\lambda_{m} \sigma^{2}\right)\left(2 b h-\beta^{2}+2 h \lambda_{m} \sigma^{2}\right)}{\left[4 b^{2} h+4 b h\left(\lambda_{m}+\lambda_{r}\right) \sigma^{2}+\lambda_{r} \sigma^{2}\left(-\beta^{2}+2 h \lambda_{m} \sigma^{2}\right)\right]^{2}},
\end{aligned}
$$

so when $h<\left(\beta^{2} / 2\left(b+\lambda_{m} \sigma^{2}\right)\right), \partial p^{m *} / \partial \lambda_{r}>0$, otherwise, $\partial p^{m *} / \partial \lambda_{r} \leq 0$. (b) Differentiating $E\left(D^{r *}\right)$ with respect to $\lambda_{r}$ and $\lambda_{m}$, respectively, we have 


$$
\begin{aligned}
& \frac{\partial E\left(D^{r *}\right)}{\partial \lambda_{r}}=\frac{4 b(\bar{a}-b c) h^{2} \sigma^{2}\left(b+\lambda_{m} \sigma^{2}\right)^{2}}{\left[4 b^{2} h+4 b h\left(\lambda_{m}+\lambda_{r}\right) \sigma^{2}+\lambda_{r} \sigma^{2}\left(-\beta^{2}+2 h \lambda_{m} \sigma^{2}\right)\right]^{2}}>0 \\
& \frac{\partial E\left(D^{r *}\right)}{\partial \lambda_{m}}=\frac{2(\bar{a}-b c) h\left(2 b h-\beta^{2}\right) \sigma^{2}\left(B_{6} h^{2}+h B_{7}+\beta^{4} \lambda_{r}^{2} \sigma^{4}\right)}{\left(-4 b h+\beta^{2}-2 h \lambda_{m} \sigma^{2}\right)^{2}\left[4 b^{2} h+4 b h\left(\lambda_{m}+\lambda_{r}\right) \sigma^{2}+\lambda_{r} \sigma^{2}\left(-\beta^{2}+2 h \lambda_{m} \sigma^{2}\right)\right]^{2}}
\end{aligned}
$$

as $B_{6}>0$ and $B_{7}^{2}-4 B_{6} \beta^{4} \lambda_{r}^{2} \sigma^{4}=-16 b^{2} \beta^{4} \lambda_{r}^{2} \sigma^{4}\left(b+\lambda_{m} \sigma^{2}\right)^{2}<0$, so when $h \leq\left(\beta^{2} /(2 b)\right), \quad \partial E\left(D^{r *}\right) / \partial \lambda_{m} \leq 0$, otherwise, $\partial E\left(D^{r *}\right) / \partial \lambda_{m}>0$, where

$$
\begin{aligned}
& B_{1}=8 b^{4}+16 b^{3}\left(\lambda_{m}+2 \lambda_{r}\right) \sigma^{2}+8 b^{2}\left(\lambda_{m}^{2}+5 \lambda_{m} \lambda_{r}+2 \lambda_{r}^{2}\right) \sigma^{4}+4 b \lambda_{m} \lambda_{r}\left(3 \lambda_{m}+4 \lambda_{r}\right) \sigma^{6}+4 \lambda_{m}^{2} \lambda_{r}^{2} \sigma^{8}, \\
& B_{2}=-12 b^{2} \beta^{2} \lambda_{r} \sigma^{2}-8 b \beta^{2} \sigma^{4} \lambda_{r}\left(\lambda_{m}+\lambda_{r}\right)-4 \beta^{2} \lambda_{m} \lambda_{r}^{2} \sigma^{6}, \\
& B_{3}=16 b^{2} h^{3} \sigma^{4}+16 b h^{3} \lambda_{r} \sigma^{6}+4 h^{2} \lambda_{r} \sigma^{6}\left(\beta^{2}+2 h \lambda_{r} \sigma^{2}\right), \\
& B_{4}=32 b^{3} h^{3} \sigma^{2}+48 b^{2} h^{2} \lambda_{r} \sigma^{4}+8 b h^{2} \beta^{2} \lambda_{r} \sigma^{4}+32 b h^{3} \lambda_{r}^{2} \sigma^{6}-4 h \beta^{2} \lambda_{r} \sigma^{4}\left(\beta^{2}+2 h \lambda_{r} \sigma^{2}\right), \\
& B_{5}=16 b^{3} h^{3}\left(b+2 \lambda_{r} \sigma^{2}\right)+8 b h \beta^{2} \lambda_{r} \sigma^{2}\left(b h-\beta^{2}\right)+16 \lambda_{r}^{2} \sigma^{4} h^{2}\left(2 b h-\beta^{2}\right)+\beta^{4} \lambda_{r} \sigma^{2}\left(\beta^{2}+2 h \lambda_{r} \sigma^{2}\right), \\
& B_{6}=8 b^{4}+16 b^{3}\left(\lambda_{m}+\lambda_{r}\right) \sigma^{2}+8 b^{2}\left(\lambda_{m}^{2}+3 \lambda_{m} \lambda_{r}+2 \lambda_{r}^{2}\right) \sigma^{4}+8 b \lambda_{m} \lambda_{r}\left(\lambda_{m}+2 \lambda_{r}\right) \sigma^{6}+4 \lambda_{m}^{2} \lambda_{r}^{2} \sigma^{8}, \\
& B_{7}=-4 b^{2} \beta^{2} \lambda_{r} \sigma^{2}-4 b \beta^{2} \sigma^{4} \lambda_{r}\left(\lambda_{m}+2 \lambda_{r}\right)-4 \beta^{2} \lambda_{m} \lambda_{r}^{2} \sigma^{6} .
\end{aligned}
$$

Proof of Proposition 3. Similar to Proposition 2, $u_{m}^{v}$ is negatively defined over $(w, e)$. As $\left(\partial^{2} u_{r}^{v} / \partial m^{2}\right)=-2 b-\lambda_{r} \sigma^{2}<0, u_{r}^{v}$ is concave over $m$.

Solving

$$
\begin{aligned}
& \frac{\partial u_{r}^{v}}{\partial m}=\bar{a}-b(2 m+w)+e \beta-m \lambda_{r} \sigma^{2}=0, \\
& \frac{\partial u_{m}^{r}}{\partial e}=-2 e h+(w-c) \beta=0, \\
& \frac{\partial u_{m}^{r}}{\partial w}=\bar{a}+b(c-m-2 w)+e \beta-(w-c) \lambda_{m} \sigma^{2}=0,
\end{aligned}
$$

there are the optimal $m^{\nu *}, w^{v *}$, and $e^{\nu *}$. Furthermore, we obtain $p^{v *}=m^{v *}+w^{v *}$.

\section{Proof of Corollary 3}

(a) From Proposition 3, differentiating $e^{\nu *}, w^{\nu *}$, and $p^{\nu *}$ with respect to $\lambda_{m}$, respectively, we obtain

$$
\begin{aligned}
& \frac{\partial e^{\nu *}}{\partial \lambda_{m}}=-\frac{2(\bar{a}-b c) h \beta \sigma^{2}\left(b+\lambda_{r} \sigma^{2}\right)\left(2 b+\lambda_{r} \sigma^{2}\right)}{\left\{6 b^{2} h+\lambda_{r} \sigma^{2}\left(-\beta^{2}+2 h \lambda_{m} \sigma^{2}\right)+b\left[-\beta^{2}+4 h\left(\lambda_{m}+\lambda_{r}\right) \sigma^{2}\right]\right\}^{2}}<0, \\
& \frac{\partial w^{\nu *}}{\partial \lambda_{m}}=-\frac{4(\bar{a}-b c) h^{2}\left(b+\lambda_{r} \sigma^{2}\right)\left(2 b \sigma^{2}+\lambda_{r} \sigma^{4}\right)}{\left\{6 b^{2} h+\lambda_{r} \sigma^{2}\left(-\beta^{2}+2 h \lambda_{m} \sigma^{2}\right)+b\left[-\beta^{2}+4 h\left(\lambda_{m}+\lambda_{r}\right) \sigma^{2}\right]\right\}^{2}}<0, \\
& \frac{\partial p^{\nu *}}{\partial \lambda_{m}}=-\frac{2(\bar{a}-b c) h \sigma^{2}\left(b+\lambda_{r} \sigma^{2}\right)\left(2 b h+\beta^{2}+2 h \lambda_{r} \sigma^{2}\right)}{\left\{6 b^{2} h+\lambda_{r} \sigma^{2}\left(-\beta^{2}+2 h \lambda_{m} \sigma^{2}\right)+b\left[-\beta^{2}+4 h\left(\lambda_{m}+\lambda_{r}\right) \sigma^{2}\right]\right\}^{2}}<0 .
\end{aligned}
$$


Similarly, differentiating $e^{\nu *}, w^{v *}$, and $p^{v *}$ with respect to $\lambda_{r}$, respectively, we obtain

$$
\begin{aligned}
& \frac{\partial e^{v *}}{\partial \lambda_{r}}=\frac{2 b(\bar{a}-b c) h \beta \sigma^{2}\left(b+\lambda_{m} \sigma^{2}\right)}{\left\{6 b^{2} h+\lambda_{r} \sigma^{2}\left(-\beta^{2}+2 h \lambda_{m} \sigma^{2}\right)+b\left[-\beta^{2}+4 h\left(\lambda_{m}+\lambda_{r}\right) \sigma^{2}\right]\right\}^{2}}>0, \\
& \frac{\partial w^{v *}}{\partial \lambda_{r}}=\frac{4 b(\bar{a}-b c) h^{2} \sigma^{2}\left(b+\lambda_{m} \sigma^{2}\right)}{\left\{6 b^{2} h+\lambda_{r} \sigma^{2}\left(-\beta^{2}+2 h \lambda_{m} \sigma^{2}\right)+b\left[-\beta^{2}+4 h\left(\lambda_{m}+\lambda_{r}\right) \sigma^{2}\right]\right\}^{2}}>0, \\
& \frac{\partial p^{\nu *}}{\partial \lambda_{r}}=-\frac{2(\bar{a}-b c) h \sigma^{2}\left(b+\lambda_{m} \sigma^{2}\right)\left(2 b h-\beta^{2}+2 h \lambda_{m} \sigma^{2}\right)}{\left\{6 b^{2} h+\lambda_{r} \sigma^{2}\left(-\beta^{2}+2 h \lambda_{m} \sigma^{2}\right)+b\left[-\beta^{2}+4 h\left(\lambda_{m}+\lambda_{r}\right) \sigma^{2}\right]\right\}^{2}},
\end{aligned}
$$

thus when $h>\left(\beta^{2} / 2\left(2 b+\lambda_{m} \sigma^{2}\right)\right), \quad\left(\partial p^{v *} / \partial \lambda_{r}\right)<0$, otherwise, $\left(\partial p^{\nu *} / \partial \lambda_{r}\right) \geq 0$

(b) Differentiating $E\left(D^{v *}\right)$ with respect to $\lambda_{r}$ and $\lambda_{m}$, respectively, we have

$$
\begin{aligned}
& \frac{\partial E\left(D^{\nu *}\right)}{\partial \lambda_{r}}=\frac{4 b(\bar{a}-b c) h^{2} \sigma^{2}\left(b+\lambda_{m} \sigma^{2}\right)^{2}}{\left\{6 b^{2} h+\lambda_{r} \sigma^{2}\left(-\beta^{2}+2 h \lambda_{m} \sigma^{2}\right)+b\left[-\beta^{2}+4 h\left(\lambda_{m}+\lambda_{r}\right) \sigma^{2}\right]\right\}^{2}}>0, \\
& \frac{\partial E\left(D^{\nu *}\right)}{\partial \lambda_{m}}=\frac{2(\bar{a}-b c) h\left(2 b h-\beta^{2}\right) \sigma^{2}\left(b+\lambda_{r} \sigma^{2}\right)^{2}}{\left\{6 b^{2} h+\lambda_{r} \sigma^{2}\left(-\beta^{2}+2 h \lambda_{m} \sigma^{2}\right)+b\left[-\beta^{2}+4 h\left(\lambda_{m}+\lambda_{r}\right) \sigma^{2}\right]\right\}^{2}},
\end{aligned}
$$

so when $h \leq \beta^{2} /(2 b), \quad \partial E\left(D^{v *}\right) / \partial \lambda_{m} \leq 0, \quad$ otherwise, Proof of Corollary 4 $\partial E\left(D^{v *}\right) / \partial \lambda_{m}>0$.

(a) From equation (10), by differentiating $u_{m}^{v *}$ with respect to $\lambda_{m}$, we have

$$
\frac{\partial u_{m}^{v *}}{\partial \lambda_{m}}=-\frac{2(\bar{a}-b c)^{2} h^{2} \sigma^{2}\left(b+\lambda_{r} \sigma^{2}\right)^{2}\left\{-3 b \beta^{2}-\beta^{2} \lambda_{r} \sigma^{2}+h\left[10 b^{2}+4 b\left(\lambda_{m}+\lambda_{r}\right) \sigma^{2}+2 \lambda_{m} \lambda_{r} \sigma^{4}\right]\right\}}{\left\{6 b^{2} h+\lambda_{r} \sigma^{2}\left(2 h \lambda_{m} \sigma^{2}-\beta^{2}\right)+b\left[4 h\left(\lambda_{m}+\lambda_{r}\right) \sigma^{2}-\beta^{2}\right]\right\}^{3}}
$$

thus when $h \leq\left(\beta^{2}\left(3 b+\lambda_{r} \sigma^{2}\right) / 2\left[5 b^{2}+2 b\left(\lambda_{m}+\right.\right.\right.$ $\left.\left.\left.\lambda_{r}\right) \sigma^{2}+\lambda_{m} \lambda_{r} \sigma^{4}\right]\right)$, we obtain $\partial u_{m}^{v *} / \partial \lambda_{m} \geq 0$, otherwise, $\partial u_{m}^{v *} / \partial \lambda_{m}<0$. Similarly, by differentiating $u_{m}^{m *}$ and $u_{m}^{r *}$ with respect to $\lambda_{m}$, respectively, we can further get $\partial u_{m}^{m *} / \partial \lambda_{m}<0$ and $\partial u_{m}^{r *} / \partial \lambda_{m}<0$. (b) From equation (7), taking the derivation of $u_{r}^{r *}$ with $\lambda_{m}$, there is

$$
\frac{\partial u_{r}^{r *}}{\partial \lambda_{m}}=\frac{4(\bar{a}-b c)^{2} h^{2}\left(2 b h-\beta^{2}\right) \sigma^{2}\left(b+\lambda_{m} \sigma^{2}\right)\left\{2\left[b^{2}+b\left(\lambda_{m}+2 \lambda_{r}\right) \sigma^{2}+\lambda_{m} \lambda_{r} \sigma^{4}\right] h-\beta^{2} \lambda_{r} \sigma^{2}\right\}}{\left(\beta^{2}-4 b h-2 h \lambda_{m} \sigma^{2}\right)^{2}\left[4 b^{2} h+4 b h\left(\lambda_{m}+\lambda_{r}\right) \sigma^{2}+\lambda_{r} \sigma^{2}\left(2 h \lambda_{m} \sigma^{2}-\beta^{2}\right)\right]^{2}},
$$


as $\quad\left(\beta^{2} / 4 b+2 \lambda_{m} \sigma^{2}\right)-\left(\beta^{2} \lambda_{r} \sigma^{2} / 2\left[b^{2}+b\left(\lambda_{m}+2 \lambda_{r}\right) \sigma^{2}+\right.\right.$ Similarly, we have $\left.\left.\lambda_{m} \lambda_{r} \sigma^{4}\right]\right)>0$, when $h>\left(\beta^{2} / 2 b\right), \partial u_{r}^{r *} / \partial \lambda_{m}>0$, otherwise, $\partial u_{r}^{r *} / \partial \lambda_{m} \leq 0$.

$$
\begin{aligned}
& \frac{\partial u_{r}^{v *}}{\partial \lambda_{m}}= \frac{4(\bar{a}-b c)^{2} h^{2}\left(2 b h-\beta^{2}\right) \sigma^{2}\left(b+\lambda_{m} \sigma^{2}\right)\left(b+\lambda_{r} \sigma^{2}\right)\left(2 b+\lambda_{r} \sigma^{2}\right)}{\left\{6 b^{2} h+\lambda_{r} \sigma^{2}\left(2 h \lambda_{m} \sigma^{2}-\beta^{2}\right)+b\left[4 h\left(\lambda_{m}+\lambda_{r}\right) \sigma^{2}-\beta^{2}\right]\right\}^{3}}, \\
& \frac{\partial u_{r}^{m *}}{\partial \lambda_{m}}=\frac{4(\bar{a}-b c)^{2} h^{2} \sigma^{2}\left(b+\lambda_{r} \sigma^{2}\right)\left(2 b+\lambda_{r} \sigma^{2}\right)^{2}\left[h\left(4 b^{2}+2 b \lambda_{r} \sigma^{2}\right)-b \beta^{2}-\beta^{2} \lambda_{r} \sigma^{2}\right]\left[b^{2}+b\left(2 \lambda_{m}+\lambda_{r}\right) \sigma^{2}+\lambda_{m} \lambda_{r} \sigma^{4}\right]}{\left\{8 b^{3} h+\lambda_{r}^{2} \sigma^{4}\left(-\beta^{2}+2 h \lambda_{m} \sigma^{2}\right)+2 b \lambda_{r} \sigma^{2}\left[-\beta^{2}+2 h\left(2 \lambda_{m}+\lambda_{r}\right) \sigma^{2}\right]+b^{2}\left[-\beta^{2}+4 h\left(2 \lambda_{m}+3 \lambda_{r}\right) \sigma^{2}\right]\right\}^{3}},
\end{aligned}
$$

and hence, when $h<\beta^{2} /(2 b), \quad \partial u_{r}^{v *} / \partial \lambda_{m} \leq 0, \quad$ As otherwise, $\partial u_{r}^{v *} / \partial \lambda_{m}>0$.

$$
\frac{\beta^{2}}{4 b+2 \lambda_{m} \sigma^{2}}-\frac{b^{2} \beta^{2}+2 b \beta^{2} \lambda_{r} \sigma^{2}+\beta^{2} \lambda_{r}^{2} \sigma^{4}}{8 b^{3}+4 b^{2}\left(2 \lambda_{m}+3 \lambda_{r}\right) \sigma^{2}+4 b \lambda_{r}\left(2 \lambda_{m}+\lambda_{r}\right) \sigma^{4}+2 \lambda_{m} \lambda_{r}^{2} \sigma^{6}}>0,
$$

if $h<\left(\beta^{2}\left(b+\lambda_{r} \sigma^{2}\right) / 2 b\left(2 b+\lambda_{r} \sigma^{2}\right)\right), \quad \partial u_{r}^{m *} / \partial \lambda_{m} \leq 0$, otherwise, $\partial u_{r}^{m *} / \partial \lambda_{m}>0$.
Proof of Corollary 5

(a) Differentiating $u_{m}^{m *}, u_{m}^{r *}$, and $u_{m}^{v *}$ with respect to $\lambda_{r}$, respectively, we have

$$
\begin{aligned}
\frac{\partial u_{m}^{m *}}{\partial \lambda_{r}}= & \frac{4 b(\bar{a}-b c)^{2} h^{2} \sigma^{2}\left(b+\lambda_{r} \sigma^{2}\right)\left[b^{2}+b\left(2 \lambda_{m}+\lambda_{r}\right) \sigma^{2}+\lambda_{m} \lambda_{r} \sigma^{4}\right]}{\left\{8 b^{3} h+\lambda_{r}^{2} \sigma^{4}\left(2 h \lambda_{m} \sigma^{2}-\beta^{2}\right)+2 b \lambda_{r} \sigma^{2}\left[2 h\left(2 \lambda_{m}+\lambda_{r}\right) \sigma^{2}-\beta^{2}\right]+b^{2}\left[4 h\left(2 \lambda_{m}+3 \lambda_{r}\right) \sigma^{2}-\beta^{2}\right]\right\}^{2}}>0, \\
\frac{\partial u_{m}^{r *}}{\partial \lambda_{r}} & =\frac{4 b(\bar{a}-b c)^{2} h^{2} \sigma^{2}\left(b+\lambda_{m} \sigma^{2}\right)\left[h\left(2 b^{2}+2 b\left(\lambda_{m}+2 \lambda_{r}\right) \sigma^{2}+2 \lambda_{m} \lambda_{r} \sigma^{4}\right)-\beta^{2} \lambda_{r} \sigma^{2}\right]}{\left[4 b^{2} h+4 b h\left(\lambda_{m}+\lambda_{r}\right) \sigma^{2}+\lambda_{r} \sigma^{2}\left(2 h \lambda_{m} \sigma^{2}-\beta^{2}\right)\right]^{3}},
\end{aligned}
$$

as $\quad\left(\beta^{2} / 4 b+2 \lambda_{m} \sigma^{2}\right)-\left(\beta^{2} \lambda_{r} \sigma^{2} / 2\left[b^{2}+b\left(\lambda_{m}+\right.\right.\right.$

$\left.\left.\left.2 \lambda_{r}\right) \sigma^{2}+\lambda_{m} \lambda_{r} \sigma^{4}\right]\right)>0,\left(\partial u_{m}^{r *} / \partial \lambda_{r}\right)>0$ :

$$
\frac{\partial u_{m}^{v *}}{\partial \lambda_{r}}=\frac{4 b(\bar{a}-b c)^{2} h^{2} \sigma^{2}\left(b+\lambda_{m} \sigma^{2}\right)\left(4 b h-\beta^{2}+2 h \lambda_{m} \sigma^{2}\right)\left(b+\lambda_{r} \sigma^{2}\right)}{\left\{6 b^{2} h+\lambda_{r} \sigma^{2}\left(-\beta^{2}+2 h \lambda_{m} \sigma^{2}\right)+b\left[-\beta^{2}+4 h\left(\lambda_{m}+\lambda_{r}\right) \sigma^{2}\right]\right\}^{3}}>0
$$

(b) From equation (3), taking the derivation of $u_{r}^{m *}$ with $\lambda_{r}$, there is

$$
\frac{\partial u_{r}^{m *}}{\partial \lambda_{r}}=\frac{-2(\bar{a}-b c)^{2} h^{2} \sigma^{2}\left[b^{2}+b\left(2 \lambda_{m}+\lambda_{r}\right) \sigma^{2}+\lambda_{m} \lambda_{r} \sigma^{4}\right]\left(C_{2} h-C_{1}\right)}{\left\{8 b^{3} h+\lambda_{r}^{2} \sigma^{4}\left(2 h \lambda_{m} \sigma^{2}-\beta^{2}\right)+2 b \lambda_{r} \sigma^{2}\left[2 h\left(2 \lambda_{m}+\lambda_{r}\right) \sigma^{2}-\beta^{2}\right]+b^{2}\left[4 h\left(2 \lambda_{m}+3 \lambda_{r}\right) \sigma^{2}-\beta^{2}\right]\right\}^{3}},
$$


where

$$
\begin{aligned}
C_{1}= & 3 b^{4} \beta^{2}+b^{3} \beta^{2}\left(10 \lambda_{m}+7 \lambda_{r}\right) \sigma^{2}+b^{2} \beta^{2} \lambda_{r}\left(17 \lambda_{m}+5 \lambda_{r}\right) \sigma^{4}+b \beta^{2} \lambda_{r}^{2}\left(8 \lambda_{m}+\lambda_{r}\right) \sigma^{6}+\beta^{2} \lambda_{m} \lambda_{r}^{3} \sigma^{8}, \\
C_{2}= & 8 b^{5}+20 b^{4}\left(2 \lambda_{m}+\lambda_{r}\right) \sigma^{2}+16 b^{3}\left(\lambda_{m}^{2}+4 \lambda_{m} \lambda_{r}+\lambda_{r}^{2}\right) \sigma^{4}+2 b^{2} \lambda_{r}\left(12 \lambda_{m}^{2}+17 \lambda_{m} \lambda_{r}+2 \lambda_{r}^{2}\right) \sigma^{6} \\
& +6 b \lambda_{m} \lambda_{r}^{2}\left(2 \lambda_{m}+\lambda_{r}\right) \sigma^{8}+2 \lambda_{m}^{2} \lambda_{r}^{3} \sigma^{10},
\end{aligned}
$$

so only when $C_{2} h-C_{1}>0$ will $\left(\partial u_{r}^{m *} / \partial \lambda_{r}\right)<0$; thus, when $h>C_{1} / C_{2},\left(\partial u_{r}^{m *} / \partial \lambda_{r}\right)<0$.

From equation (7), taking the derivation of $u_{r}^{r *}$ with $\lambda_{r}$, there is

$$
\frac{\partial u_{r}^{r *}}{\partial \lambda_{r}}=-\frac{2(\bar{a}-b c)^{2} h^{2} \sigma^{2}\left(b+\lambda_{m} \sigma^{2}\right)^{2}}{\left[4 b^{2} h+4 b h\left(\lambda_{m}+\lambda_{r}\right) \sigma^{2}+\lambda_{r} \sigma^{2}\left(-\beta^{2}+2 h \lambda_{m} \sigma^{2}\right)\right]^{2}}<0
$$

Differentiating $u_{r}^{v *}$ with respect to $\lambda_{r}$, we have

$$
\frac{\partial u_{r}^{\nu *}}{\partial \lambda_{r}}=-\frac{2(\bar{a}-b c)^{2} h^{2} \sigma^{2}\left(b+\lambda_{m} \sigma^{2}\right)^{2}\left[h\left(10 b^{2}+4 b\left(\lambda_{m}+\lambda_{r}\right) \sigma^{2}+2 \lambda_{m} \lambda_{r} \sigma^{4}\right)-3 b \beta^{2}-\beta^{2} \lambda_{r} \sigma^{2}\right]}{\left\{6 b^{2} h+\lambda_{r} \sigma^{2}\left(2 h \lambda_{m} \sigma^{2}-\beta^{2}\right)+b\left[4 h\left(\lambda_{m}+\lambda_{r}\right) \sigma^{2}-\beta^{2}\right]\right\}^{3}},
$$

as $\quad\left(\beta^{2}\left(3 b+\lambda_{r} \sigma^{2}\right) / 2\left(5 b^{2}+2 b\left(\lambda_{m}+\lambda_{r}\right) \sigma^{2}+\lambda_{m} \lambda_{r} \sigma^{4}\right)\right)>$ $\left(\beta^{2} / 4 b+2 \lambda_{m} \sigma^{2}\right)$, and we obtain if $h>\left(\beta^{2}\left(3 b+\lambda_{r} \sigma^{2}\right) / 2\left(5 b^{2}+2 b\left(\lambda_{m}+\lambda_{r}\right) \sigma^{2}+\lambda_{m} \lambda_{r} \sigma^{4}\right)\right)$, $\partial u_{r}^{v *} / \partial \lambda_{r}<0$, otherwise, $\partial u_{r}^{v *} / \partial \lambda_{r} \geq 0$.
Proof of Proposition 4

(a) Comparing $m^{\nu *}$ and $m^{r *}$, we obtain

$$
m^{v *}-m^{r *}=\frac{-2 b(\bar{a}-b c) h\left(2 b h-\beta^{2}\right)\left(b+\lambda_{m} \sigma^{2}\right)}{B\left\{6 b^{2} h+\lambda_{r} \sigma^{2}\left(2 h \lambda_{m} \sigma^{2}-\beta^{2}\right)+b\left[4 h\left(\lambda_{m}+\lambda_{r}\right) \sigma^{2}-\beta^{2}\right]\right\}},
$$

so when $h \geq \beta^{2} /(2 b), \quad m^{v *} \leq m^{r *}, \quad$ otherwise,

(b) After comparing $e^{\nu *}$ and $e^{r *}$, there is

$m^{v *}>m^{r *}$.

$$
e^{v *}-e^{r *}=\frac{2 b^{2}(\bar{a}-b c) h \beta\left(2 b h-\beta^{2}\right)\left(b+\lambda_{m} \sigma^{2}\right)}{\left(4 b h-\beta^{2}+2 h \lambda_{m} \sigma^{2}\right) B\left\{6 b^{2} h+\lambda_{r} \sigma^{2}\left(2 h \lambda_{m} \sigma^{2}-\beta^{2}\right)+b\left[4 h\left(\lambda_{m}+\lambda_{r}\right) \sigma^{2}-\beta^{2}\right]\right\}},
$$

that is, when $h \geq \beta^{2} /(2 b), \quad e^{v *} \geq e^{r *}$, otherwise, $e^{v *}<e^{r *}$.

By comparing $e^{m *}$ and $e^{r *}$, we have

$$
e^{r *}-e^{m *}=\frac{2 b h(\bar{a}-b c) \beta\left\{B_{3} h+\left[b^{3} \beta^{2}+b^{2} \beta^{2} \lambda_{m} \sigma^{2}-b \beta^{2} \lambda_{r}\left(\lambda_{m}+\lambda_{r}\right) \sigma^{4}-\beta^{2} \lambda_{m} \lambda_{r}^{2} \sigma^{6}\right]\right\}}{\left[4 A b h\left(b+\lambda_{m} \sigma^{2}\right)+2 h \lambda_{m} b^{2} \sigma^{2}+A^{2}\left(4 b h-\beta^{2}+2 h \lambda_{m} \sigma^{2}\right)\right]\left(4 b h-\beta^{2}+2 h \lambda_{m} \sigma^{2}\right) B},
$$

where $C_{3}=4 b^{3}\left(\lambda_{m}+\lambda_{r}\right) \sigma^{2}+4 b^{2}\left(\lambda_{m}^{2}+3 \lambda_{m} \lambda_{r}+\lambda_{r}^{2}\right) \sigma^{4}+$ $6 b \lambda_{m} \lambda_{r}\left(\lambda_{m}+\lambda_{r}\right) \sigma^{6}+2 \lambda_{m}^{2} \lambda_{r}^{2} \sigma^{8}$, as 


$$
\frac{\beta^{2}}{2\left(2 b+\lambda_{m} \sigma^{2}\right)}-\frac{b \beta^{2} \lambda_{r}\left(\lambda_{m}+\lambda_{r}\right) \sigma^{4}+\beta^{2} \lambda_{m} \lambda_{r}^{2} \sigma^{6}-b^{3} \beta^{2}-b^{2} \beta^{2} \lambda_{m} \sigma^{2}}{C_{3}}>0, \quad e^{r *}>e^{m *}
$$

(c) From $w^{v *}$ and $w^{r *}$, we can have

$$
w^{v *}-w^{r *}=\frac{4 b^{2}(\bar{a}-b c) h^{2}\left(2 b h-\beta^{2}\right)\left(b+\lambda_{m} \sigma^{2}\right)}{\left(4 b h-\beta^{2}+2 h \lambda_{m} \sigma^{2}\right) B\left\{6 b^{2} h+\lambda_{r} \sigma^{2}\left(2 h \lambda_{m} \sigma^{2}-\beta^{2}\right)+b\left[4 h\left(\lambda_{m}+\lambda_{r}\right) \sigma^{2}-\beta^{2}\right]\right\}},
$$

so when $h \geq \beta^{2} /(2 b), w^{v *} \geq w^{r *}$. By comparing $w^{v *}$ and $w^{m *}$, we obtain, when $h \leq\left(\beta^{2}\left(b+\lambda_{r} \sigma^{2}\right) /\right.$ $\left.2 b\left(2 b+\lambda_{r} \sigma^{2}\right)\right), \quad w^{v *} \geq w^{m *}$. As $\beta^{2} /(2 b)>\left(\beta^{2}(b+\right.$ $\left.\left.\lambda_{r} \sigma^{2}\right) / 2 b\left(2 b+\lambda_{r} \sigma^{2}\right)\right)$, we get the results. (d) By comparing $p^{r *}$ and $p^{v *}$, we can obtain

$$
p^{r *}-p^{v *}=\frac{2 b(\bar{a}-b c) h\left(\left(b+\lambda_{m} \sigma^{2}\right)\left(2 b h-\beta^{2}\right)\left(2 b h-\beta^{2}+2 h \lambda_{m} \sigma^{2}\right)\right.}{\left(4 b h-\beta^{2}+2 h \lambda_{m} \sigma^{2}\right) B\left\{6 b^{2} h+\lambda_{r} \sigma^{2}\left(2 h \lambda_{m} \sigma^{2}-\beta^{2}\right)+b\left[4 h\left(\lambda_{m}+\lambda_{r}\right) \sigma^{2}-\beta^{2}\right]\right\}} .
$$

So, when $\beta^{2} /\left(2\left(b+\lambda_{m} \sigma^{2}\right)\right)<h \leq \beta^{2} /(2 b), p^{r *}<p^{v *}$; when $h \leq \beta^{2} /\left(2\left(b+\lambda_{m} \sigma^{2}\right)\right)$ or $h \geq \beta^{2} /(2 b), p^{r *} \geq p^{\nu *}$.

Similarly, we can obtain that when $h \geq \beta^{2}[b+$ $\left.\left(\lambda_{m}+\lambda_{r}\right) \sigma^{2}\right] / 2 b\left(b+\lambda_{r} \sigma^{2}\right), p^{m *} \geq p^{\nu *}$, otherwise, $p^{m *}<p^{v *}$. Furthermore, as $\left(\beta^{2}\left[b+\left(\lambda_{m}+\lambda_{r}\right) \sigma^{2}\right] / 2 b\left(b+\lambda_{r} \sigma^{2}\right)\right)>$ $\beta^{2} /(2 b)$, we get the other results.

\section{Proof of Proposition 5}

(a) Comparing $u_{r}^{r *}$ and $u_{r}^{v *}$, there is

$$
u_{r}^{r *}-u_{r}^{v *}=\frac{2 b^{2}(\bar{a}-b c)^{2} h^{2}\left(\beta^{2}-2 b h\right)^{2}\left(b+\lambda_{m} \sigma^{2}\right)^{2}}{\left(4 b h-\beta^{2}+2 h \lambda_{m} \sigma^{2}\right) B\left\{6 b^{2} h+\lambda_{r} \sigma^{2}\left(2 h \lambda_{m} \sigma^{2}-\beta^{2}\right)+b\left[4 h\left(\lambda_{m}+\lambda_{r}\right) \sigma^{2}-\beta^{2}\right]\right\}^{2}} \geq 0,
$$

that is, $u_{r}^{r *} \geq u_{r}^{v *}$. Similarly, we can get $u_{r}^{v *}>u_{r}^{m *}$.

Thus, $u_{r}^{r *} \geq u_{r}^{v *}>u_{r}^{m *}$.

(b) Comparing $u_{m}^{r *}$ and $u_{m}^{v *}$, there is

$$
\begin{gathered}
u_{m}^{r *}-u_{m}^{v *}=\left\{\frac{B-2 b h\left(b+\lambda_{m} \sigma^{2}\right)}{B}+\frac{\left(4 b h-\beta^{2}+2 h \lambda_{m} \sigma^{2}\right)\left(b+\lambda_{r} \sigma^{2}\right)}{6 b^{2} h+\lambda_{r} \sigma^{2}\left(2 h \lambda_{m} \sigma^{2}-\beta^{2}\right)+b\left[4 h\left(\lambda_{m}+\lambda_{r}\right) \sigma^{2}-\beta^{2}\right]}\right\} * \\
\frac{(\bar{a}-b c)^{2} h}{\left(4 b h-\beta^{2}+2 h \lambda_{m} \sigma^{2}\right)} * \frac{-2 b^{2} h\left(2 b h-\beta^{2}\right)\left(b+\lambda_{m} \sigma^{2}\right)}{B\left\{6 b^{2} h+\lambda_{r} \sigma^{2}\left(2 h \lambda_{m} \sigma^{2}-\beta^{2}\right)+b\left[4 h\left(\lambda_{m}+\lambda_{r}\right) \sigma^{2}-\beta^{2}\right]\right\}},
\end{gathered}
$$

and thus, we know that when $h>\beta^{2} /(2 b), u_{m}^{v *}>u_{m}^{r *}$. In the same way, we can get (c). 


\section{Data Availability}

No data were used to support this study.

\section{Conflicts of Interest}

The authors declare that there are no conflicts of interest regarding the publication of this paper.

\section{Acknowledgments}

This research was supported in part by the National Natural Science Foundation of China under Grant nos. 71601098 and 71502084, Ministry of Education of Humanities and Social Science Project no. 20YJA630086, and 2019 Qinglan Project of Jiangsu Province in China, Collaborative Innovation Center of Audit Information Engineering and Technology no. 18CICA05.

\section{References}

[1] B. Shen, T.-M. Choi, and H.-L. Chan, "Selling green first or not? A Bayesian analysis with service levels and environmental impact considerations in the Big Data Era," Technological Forecasting and Social Change, vol. 144, no. 7, pp. 412-420, 2019.

[2] A. Yenipazarli, "To collaborate or not to collaborate: prompting upstream eco-efficient innovation in a supply chain," European Journal of Operational Research, vol. 260, no. 2, pp. 571-587, 2017.

[3] Z. Hong and X. Guo, "Green product supply chain contracts considering environmental responsibilities," Omega, vol. 83, pp. 155-166, 2019.

[4] X. Shi, Y. Qian, and C. Dong, "Economic and environmental performance of fashion supply chain: the joint effect of power structure and sustainable investment," Sustainability, vol. 9, no. 6, pp. 961-983, 2017.

[5] S. M. Gilbert and V. Cvsa, "Strategic commitment to price to stimulate downstream innovation in a supply chain," European Journal of Operational Research, vol. 150, no. 3, pp. 617-639, 2003.

[6] B. Niu, L. Chen, and J. Zhang, "Sustainability analysis of supply chains with fashion products under alternative power structures and loss-averse supplier," Sustainability, vol. 9, no. 6, pp. 995-1014, 2017.

[7] A. J. Dukes, T. Geylani, and K. Srinivasan, "Strategic assortment reduction by a dominant retailer," Marketing Science, vol. 28, no. 2, pp. 309-319, 2009.

[8] M. C. Cohen, R. Lobel, and G. Perakis, "The impact of demand uncertainty on consumer subsidies for green technology adoption," Management Science, vol. 62, no. 5, pp. 1235-1258, 2016.

[9] H. L. Chan, T. M. Choi, Y. J. Cai, and B. Shen, "Environmental taxes in newsvendor supply chains: a mean-downside-risk analysis," IEEE Transactions on Systems, Man, and Cybernetics: Systems, pp. 1-14, 2018.

[10] X. H. Gan, S. P. Sethi, and H. M. Yan, "Coordination of supply chains with risk-averse agents," Production and Operations Management, vol. 13, no. 2, pp. 135-149, 2004.

[11] D. F. Drake, P. R. Kleindorfer, and L. N. Van Wassenhove, "Technology choice and capacity portfolios under emissions regulation," Production and Operations Management, vol. 25, no. 6, pp. 1006-1025, 2016.
[12] L. Yang, Q. Zhang, and J. Ji, "Pricing and carbon emission reduction decisions in supply chains with vertical and horizontal cooperation," International Journal of Production Economics, vol. 191, pp. 286-297, 2017.

[13] P. Ma, J. Shang, and H. Wang, "Enhancing corporate social responsibility: contract design under information asymmetry," Omega, vol. 67, pp. 19-30, 2017.

[14] H. L. Lee and C. S. Tang, "Socially and environmentally responsible value chain innovations: new operations management research opportunities," Management Science, vol. 64, no. 3, pp. 983-996, 2018.

[15] S. Swami and J. Shah, "Channel coordination in green supply chain management," Journal of the Operational Research Society, vol. 64, no. 3, pp. 336-351, 2013.

[16] C. Dong, Q. Liu, and B. Shen, "To be or not to be green? Strategic investment for green product development in a supply chain," Transportation Research Part E: Logistics and Transportation Review, vol. 131, pp. 193-227, 2019.

[17] B. Shen, C. Zhu, Q. Li, and X. Wang, "Green technology adoption in textiles and apparel supply chains with environmental taxes," International Journal of Production Research, pp. 1-18, 2020.

[18] Z. L. Liu, T. D. Anderson, and J. M. Cruz, "Consumer environmental awareness and competition in two-stage supply chains," European Journal of Operational Research, vol. 218, no. 3, pp. 602-613, 2012.

[19] A. A. Taleizadeh and H. Heydarian, "Pricing, refund, and coordination optimization in a two stages supply chain of green and non-green products under hybrid production mode," Journal of Remanufacturing, vol. 7, no. 1, pp. 49-76, 2017.

[20] B. Shen, Y. Cao, and X. Xu, "Product line design and quality differentiation for green and non-green products in a supply chain," International Journal of Production Research, vol. 58, no. 1, pp. 148-164, 2020.

[21] M. R. Galbreth and B. Ghosh, "Competition and sustainability: the impact of consumer awareness," Decision Sciences, vol. 44, no. 1, pp. 127-159, 2013.

[22] L. Zhang, J. Wang, and J. You, "Consumer environmental awareness and channel coordination with two substitutable products," European Journal of Operational Research, vol. 241, no. 1, pp. 63-73, 2015.

[23] D. Kartick, R. Sankhadip, and S. Subrata, "The impact of strategic inventory and procurement strategies on green product design in a two-period supply chain," International Journal of Production Research, vol. 57, no. 7, pp. 1915-1948, 2019.

[24] D. Yang, T. Xiao, and J. Huang, "Dual-channel structure choice of an environmental responsibility supply chain with green investment," Journal of Cleaner Production, vol. 210, pp. 134-145, 2019.

[25] S. Guo, T.-M. Choi, and B. Shen, "Green product development under competition: a study of the fashion apparel industry," European Journal of Operational Research, vol. 280, no. 2, pp. 523-538, 2020.

[26] A. Raj, I. Biswas, and S. K. Srivastava, "Designing supply contracts for the sustainable supply chain using game theory," Journal of Cleaner Production, vol. 185, pp. 275-284, 2018.

[27] M. Y. Jaber, C. H. Glock, and A. M. A. El Saadany, "Supply chain coordination with emissions reduction incentives," International Journal of Production Research, vol. 51, no. 1, pp. 69-82, 2013.

[28] T. A. Allah, A. B. Nima, and B. R. Sarker, "Coordinated contracts in a two-echelon green supply chain considering 
pricing strategy," Computers \& Industrial Engineering, vol. 124, pp. 249-275, 2018.

[29] R. Shi, J. Zhang, and J. Ru, "Impacts of power structure on supply chains with uncertain demand," Production and Operations Management, vol. 22, no. 5, pp. 1232-1249, 2013.

[30] S. C. Choi, "Price competition in a channel structure with a common retailer," Marketing Science, vol. 10, no. 4, pp. 271-296, 1991.

[31] C.-H. Wu, C.-W. Chen, and C.-C. Hsieh, "Competitive pricing decisions in a two-echelon supply chain with horizontal and vertical competition," International Journal of Production Economics, vol. 135, no. 1, pp. 265-274, 2012.

[32] Z. Luo, X. Chen, J. Chen, and X. Wang, "Optimal pricing policies for differentiated brands under different supply chain power structures," European Journal of Operational Research, vol. 259, no. 2, pp. 437-451, 2016.

[33] G. Cai, Z. G. Zhang, and M. Zhang, "Game theoretical perspectives on dual-channel supply chain competition with price discounts and pricing schemes," International Journal of Production Economics, vol. 117, no. 1, pp. 80-96, 2009.

[34] T. Li, R. Zhang, and B. Liu, "Pricing decisions of competing supply chains under power imbalance structures," Computers \& Industrial Engineering, vol. 125, pp. 695-707, 2018.

[35] Z. Luo, X. Chen, and M. Kai, "The effect of customer value and power structure on retail supply chain product choice and pricing decisions," Omega, vol. 77, pp. 115-126, 2018.

[36] Y. Yu and T. Xiao, "Pricing and cold-chain service level decisions in a fresh agri-products supply chain with logistics outsourcing," Computers \& Industrial Engineering, vol. 111, pp. 56-66, 2017.

[37] A. Touboulic, D. Chicksand, and H. Walker, "Managing imbalanced supply chain relationships for sustainability: a power perspective," Decision Sciences, vol. 45, no. 4, pp. 577-619, 2014.

[38] X. Chen, X. Wang, and H. K. Chan, "Manufacturer and retailer coordination for environmental and economic competitiveness: a power perspective," Transportation Research Part E: Logistics and Transportation Review, vol. 97, no. 1, pp. 268-281, 2017.

[39] B. Shen, S. Liu, T. Zhang, and T.-M. Choi, "Optimal advertising and pricing for new green products in the circular economy," Journal of Cleaner Production, vol. 233, pp. 314327, 2019.

[40] A. Ghavamifar, A. Makui, and A. A. Taleizadeh, "Designing a resilient competitive supply chain network under disruption risks: a real-world application," Transportation Research Part E: Logistics and Transportation Review, vol. 115, pp. 87-109, 2018.

[41] C. S. Tang, "Perspectives in supply chain risk management," International Journal of Production Economics, vol. 103, no. 2, pp. 451-488, 2006.

[42] R. Wang and J. Wang, "Procurement strategies with quantityoriented reference point and loss aversion," Omega, vol. 80, pp. 1-11, 2018.

[43] J. Wu, J. Li, S. Wang, and T. Cheng, "Mean-variance analysis of the newsvendor model with stockout cost $\boldsymbol{z}^{2}$," Omega, vol. 37, no. 3, pp. 724-730, 2009.

[44] B. Shen, X. Wang, Y. F. Cao, and Q. Y. Li, "Financing decisions in supply chains with a capital-constrained manufacturer: competition and risk," International Transactions in Operational Research, vol. 27, no. 5, pp. 2658-2682, 2020.

[45] T. Xiao and D. Yang, "Price and service competition of supply chains with risk-averse retailers under demand uncertainty,"
International Journal of Production Economics, vol. 114, no. 1, pp. 187-200, 2008.

[46] A. A. Tsay, "Risk sensitivity in distribution channel partnerships: implications for manufacturer return policies," Journal of Retailing, vol. 78, no. 2, pp. 147-160, 2002.

[47] W. Zhuo, L. Shao, and H. Yang, "Mean-variance analysis of option contracts in a two-echelon supply chain," European Journal of Operational Research, vol. 271, no. 2, pp. 535-547, 2018.

[48] T.-M. Choi, C. Ma, B. Shen, and Q. Sun, "Optimal pricing in mass customization supply chains with risk-averse agents and retail competition," Omega, vol. 88, pp. 150-161, 2019.

[49] G. Xie, W. Yue, S. Wang, and K. K. Lai, "Quality investment and price decision in a risk-averse supply chain," European Journal of Operational Research, vol. 214, no. 2, pp. 403-410, 2011.

[50] A. A. Taleizadeh, M. S. Moshtagh, and I. Moon, "Pricing, product quality, and collection optimization in a decentralized closed-loop supply chain with different channel structures: game Theoretical Approach," Journal of Cleaner Production, vol. 189, no. 10, pp. 406-431, 2018.

[51] A. A. Taleizadeh, E. Sane-Zerang, and T.-M. Choi, "The effect of marketing effort on dual-channel closed-loop supply chain systems," IEEE Transactions on Systems, Man, and Cybernetics: Systems, vol. 48, no. 2, pp. 265-276, 2018.

[52] S. M. Disney and D. R. Towill, "The effect of vendor managed inventory (VMI) dynamics on the Bullwhip Effect in supply chains," International Journal of Production Economics, vol. 85, no. 2, pp. 199-215, 2003.

[53] T. L. Zhang, L. Liang, Y. G. Yu, and Y. Yu, “An integrated vendor-managed inventory model for a two-echelon system with order cost reduction," International Journal of Production Economics, vol. 109, no. 1-2, pp. 241-253, 2007.

[54] H. Krishnan, R. Kapuscinski, and D. A. Butz, "Quick response and retailer effort," Management Science, vol. 56, no. 6, pp. 962-977, 2010.

[55] V. Agrawal and S. Seshadri, "Risk intermediation in supply chains," IIE Transactions, vol. 32, no. 9, pp. 819-831, 2000.

[56] S. Gupta and R. Loulou, "Process innovation, product differentiation, and channel structure: strategic incentives in a duopoly," Marketing Science, vol. 17, no. 4, pp. 301-316, 1998. 